\title{
Metagenomic analysis reveals large potential for carbon, nitrogen and sulfur cycling in coastal methanic sediments of the Bothnian Sea
}

Olivia Rasigraf ${ }^{1,2, *}$, , Niels A.G.M. van Helmond ${ }^{3}$, Jeroen Frank ${ }^{1,4}$, Wytze K. Lenstra ${ }^{3}$, Matthias Egger $^{3, \#}$, Caroline P. Slomp ${ }^{2,3}$, Mike S.M. Jetten ${ }^{1,2,4}$

${ }^{1}$ Department of Microbiology, Radboud University Nijmegen, Nijmegen, The Netherlands

${ }^{2}$ Netherlands Earth System Science Centre (NESSC), Utrecht, The Netherlands

${ }^{3}$ Department of Earth Sciences, Utrecht University, The Netherlands

${ }^{4}$ Soehngen Institute of Anaerobic Microbiology (SIAM), Radboud University Nijmegen, Nijmegen, The Netherlands

*current address: German Research Centre for Geosciences (GFZ), Section 3.7

Geomicrobiology, Potsdam, Germany

\# current address: The Ocean Cleanup, Rotterdam, The Netherlands

§corresponding author: olivia.rasigraf@gfz-potsdam.de 
3 The Bothnian Sea is an oligotrophic brackish basin characterized by low salinity and high

4 concentrations of reactive iron, methane and ammonium in the sediments potentially enabling an

5 intricate microbial network. Therefore, we analyzed and compared biogeochemical and microbial

6 profiles at one offshore and two near coastal sites in the Bothnian Sea. 16S rRNA amplicon

7 sequence analysis revealed stratification of both bacterial and archaeal taxa in accordance with

8 the geochemical gradients of iron, sulfate and methane. The communities at the two near coastal

9 sites were more similar to each other than that at the offshore site located at a greater water depth.

10 To obtain insights into the metabolic networks within the iron-rich methanic sediment layer

11 located below the sulfate-methane transition zone (SMTZ), we performed metagenomic

12 sequencing of sediment-derived DNA. Genome bins retrieved from the most abundant bacterial

13 and archaeal community members revealed a broad potential for respiratory sulfur metabolism

14 via partially reduced sulfur species. Nitrogen cycling was dominated by reductive processes via a

15 truncated denitrification pathway encoded exclusively by bacterial lineages. Gene-centric

16 fermentative metabolism analysis indicated the central role of acetate, formate, alcohols and

17 hydrogen in the analyzed anaerobic sediment. Methanogenic/-trophic pathways were dominated

18 by Methanosaetaceae, Methanosarcinaceae, Methanomassiliicoccaceae, Methanoregulaceae and

19 ANME-2 archaea. Thorarchaeota and Bathyarchaeota encoded pathways for acetogenesis. Our

20 results indicate flexible metabolic capabilities of core community bacterial and archaeal taxa,

21 which can adapt to changing redox conditions, and with a spatial distribution in Bothnian Sea

22 sediments that is likely governed by the quality of available organic substrates. 


\section{Introduction}

26 Sediment microbial communities drive biogeochemical cycles through their specific metabolic

27 activities. The supply of organic carbon from primary production or terrestrial input via rivers,

28 and electron acceptors such as nitrate $\left(\mathrm{NO}_{3}{ }^{-}\right)$and sulfate $\left(\mathrm{SO}_{4}{ }^{2-}\right)$ in marine systems, will select for

29 particular microbial guilds. Together they will determine the establishment of environment-

30 specific metabolic networks and geochemical profiles. Despite the critical role of coastal

31 sediments in global biogeochemical cycling, for example, as a source of methane $\left(\mathrm{CH}_{4}\right)($ Bange

32 et al. 1994) and sink for nutrients (Asmala et al. 2017), our understanding of their microbial

33 community composition and how this is linked to the cycling of sulfur (S), carbon (C) and

34 nitrogen $(\mathrm{N})$, is still incomplete.

35 The Bothnian Sea, a brackish basin located in the northern part of the Baltic Sea, is an ideal

36 location to study the linkage between microbes and biogeochemistry because of the distinct sharp

37 redox zonation of its surface sediments (Egger et al. 2015a; Lenstra et al. 2018; Rasigraf et al.

38 2017). The Bothnian Sea is oligotrophic and most organic matter in the sediment is supplied

39 through rivers and is thus of terrestrial origin (Algesten et al. 2006). $\mathrm{SO}_{4}{ }^{2-}$ concentrations in the

40 bottom water are low (3-5 mM), which has allowed the development of a relatively shallow $\mathrm{SO}_{4}{ }^{2-}$

41 reduction zone in the sediment at sites with relatively high sedimentation rates. At such sites, $\mathrm{CH}_{4}$

42 is abundant in the lower part of the $\mathrm{SO}_{4}{ }^{2-}$ reduction zone, and a distinct sulfate-methane transition

43 zone (SMTZ) has developed (Egger et al. 2015a; Lenstra et al. 2018). The exact position of the

44 SMTZ varies with space and time depending on the sedimentation rate and the input of organic

45 matter (Egger et al. 2015a; Lenstra et al. 2018; Rooze et al. 2016; Slomp et al. 2013). The input

46 of reactive iron (oxyhydroxides, henceforth termed Fe oxides) is in general higher than sulfide 
$47\left(\mathrm{H}_{2} \mathrm{~S}\right)$ formation in the sediment resulting in net burial of Fe oxides below the SMTZ. Both

48 modeling and incubation studies suggest $\mathrm{CH}_{4}$ oxidation with Fe oxides as the electron acceptor in

49 the $\mathrm{SO}_{4}{ }^{2-}$-depleted methanic layers below the SMTZ (Egger et al. 2015b; Rooze et al. 2016;

50 Slomp et al. 2013). So far, the underlying pathways and responsible organisms for this process

51 are largely unknown.

52 Several studies have investigated the microbial community composition in sediments of the

53 Bothnian Bay and North Sea with 16S rRNA pyrosequencing techniques and speculated on

54 possible microbial guilds involved in $\mathrm{CH}_{4}$ and Fe cycling (Oni et al. 2015a; Reyes et al. 2016). In

55 surface sediments from the Skagerrak and Bothnian Bay, various potential Fe-reducers belonging

56 to Desulfobulbaceae, Desulfuromonadaceae and Pelobacteraceae families were identified

57 (Reyes et al. 2016). In deeper methanic sediment layers of the Helgoland area in the North Sea,

58 microbial populations predicted to be involved in $\mathrm{Fe}$ and $\mathrm{CH}_{4}$ cycling included uncultured

59 lineages of candidate division JS1 and methanogenic/-trophic archaea belonging to

60 Methanohalobium, Methanosaeta and anaerobic methane oxidizing archaea clade 3 (ANME-3)

61 (Oni et al. 2015a). Moreover, recent findings indicate that temperature is another factor which

62 can influence the pathway of crystalline Fe utilization in these sediments (Aromokeye et al.

63 2018). Investigations of microbial communities involved in Fe cycling are challenging due to the

64 absence of suitable 'universal' biomarkers. Different microbial groups have evolved different

65 mechanisms and underlying genes encoding responsible enzymes may be unrelated. Novel

66 mechanisms with unknown enzymatic steps in Fe reduction may exist but would remain

67 undetected.

68 Activity measurements and functional biomarker analysis showed the presence of various 69 pathways for N cycling in the Bothnian Sea and Bothnian Bay sediments (Bonaglia et al. 2017; 
Hellemann et al. 2017; Rasigraf et al. 2017; Reyes et al. 2017). Thus, for example, dissimilatory

71 nitrate reduction to ammonium (DNRA) and denitrification were shown to be of nearly equal

72 importance in oligotrophic sediments at a coastal site in the Bothnian Bay (Bonaglia et al. 2017).

73 These results contradict the common assumption that DNRA is of minor importance in

74 oligotrophic sediments with low organic carbon input and low rates of $\mathrm{H}_{2} \mathrm{~S}$ production. Also, a

75 gene-centric approach for N-cycle potential was applied previously to the Bothnian Sea and

76 Bothnian Bay sediments. Sediment from the surface layer, SMTZ and deep methanic zone were

77 analyzed and showed that $\mathrm{N}$ cycling genes were most abundant in the surface layer with

78 denitrification being potentially the dominant pathway for $\mathrm{N}$ loss (Rasigraf et al. 2017).

79 Furthermore, in suboxic sediments from the Bothnian Bay, the genetic potential for

80 denitrification was far greater than that for DNRA (Reyes et al. 2017). With respect to the

81 nitrification potential, differences were found between analyzed sites in the Bothnian Sea and

82 Bothnian Bay. While in the central part of the Bothnian Sea, the nitrification potential was almost

83 exclusively attributed to ammonia oxidizing archaea (AOA) belonging to Thaumarchaeota

84 Marine Group-I (MG-I) (Rasigraf et al. 2017), in suboxic coastal sediments in the Bothnian Bay,

85 both AOA and ammonia oxidizing bacteria (AOB) seemed equally important (Reyes et al. 2017).

86 Thus, large differences in measured activities and genetic inventory can occur between sediments

87 in the same region. The environmental factors driving those differences are not well explored.

88 Here, we assessed the microbial community composition in sediments at three sites along a water

89 depth gradient in the Bothnian Sea by various complementary approaches including 16S rRNA

90 amplicon sequencing. Two sites are located near the coast in the Öre Estuary (N10 and NB8,

91 Lenstra et al. 2018) while the third site is located in the central-basin of the Bothnian Sea (US5B,

92 Egger et al. 2015a). Porewater profiles of key geochemical constituents such as $\mathrm{SO}_{4}{ }^{2-}$, dissolved 
$93 \mathrm{Fe}$ and $\mathrm{CH}_{4}$ were used to determine the redox zonation. In addition to community comparisons

94 between sites, we examined the core microbial community and its metabolic potential in the

95 ferruginous methanic zone at one of the coastal sites through metagenome sequencing. Several

96 high quality metagenome-assembled genomes (MAGs) were recovered for abundant microbial

97 community members. Analysis of the MAGs indicated a flexible metabolic network with a strong

98 potential for fermentation and S cycling.

\section{Materials and Methods}

\section{Sampling and geochemical analysis}

103 The two near-coastal sites, N10 and NB8 are located in the Öre Estuary in the Bothnian Sea at 104 water depths of 21 and $33 \mathrm{~m}$, respectively (Lenstra et al. 2018). Sediments at these sites were 105 collected during a field campaign with R/V Lotty in August 2015 using a Gemini gravity corer (8 $106 \mathrm{~cm}$ inner diameter). The offshore site US5B is located in the central basin of the Bothnian Sea at 107 a water depth of 214 m and was sampled in August 2012 as described in Egger et al. 2015a.

108 Sediments at this site were collected during a field campaign with R/V Aranda in August 2012 using a GEMAX gravity corer (10 cm inner diameter). Locations of all sampled sites are shown in Figure 1. Porewater depth profiles of $\mathrm{SO}_{4}{ }^{2-}, \mathrm{CH}_{4}, \mathrm{NH}_{4}{ }^{+}, \mathrm{H}_{2} \mathrm{~S}$ and dissolved Fe were measured 111 either onboard or later in the laboratory as described previously (Egger et al. 2015a; Lenstra et al.

112 2018; Figure 2). Sediment characteristics of sampled sites are summarized in Table 1. Sediment 113 cores were kept at $4^{\circ} \mathrm{C}$ in the dark covered with a water layer until slicing. The slicing of 114 sediment cores was performed in an anaerobic chamber under argon atmosphere. Sediment 115 subsamples dedicated for DNA isolation were stored at $-20^{\circ} \mathrm{C}$ until further processing. 


\section{DNA isolation}

118 The frozen core sediment subsamples were defrosted on ice and vortexed to obtain homogenous 119 slurry. Subsequently, $0.2-0.5 \mathrm{ml}$ of original sediment slurry was filled into a bead beating tube 120 from the PowerSoil DNA isolation kit (MoBio, USA). Further isolation was performed according 121 to manufacturer's instructions. The quantity of isolated DNA was assessed by NanoDrop 1000 122 (Thermo Scientific, USA) and Qubit ${ }^{\circledR} 2.0$ (Invitrogen, Life Technologies, Carlsbad, USA). After 123 isolation, DNA was frozen at $-20^{\circ} \mathrm{C}$ until further use.

\section{S rRNA and metagenome sequencing}

126 The amplification of total archaeal and bacterial 16S rRNA genes was performed with the 127 following primer pairs: Arch349F (5’-GYGCASCAGKCGMGAAW30) (Takai and Horikoshi 2000) and Arch806R (5’-GGACTACVSGGGTATCTAAT-3’) (Takai and Horikoshi 2000) for

129 archaea, Bac341F (5'-CCTACGGGNGGCWGCAG-3’) (Herlemann et al. 2011) and Bac806R (5’-GGACTACHVGGGTWTCTAAT-3') (Caporaso et al. 2012) for bacteria. 16S rRNA amplicon sequencing was performed on the Illumna MiSeq platform using the MiSeq Reagent

132 Kit v3, yielding 2x300bp paired-end reads (Macrogen Inc., Europe).

133 For metagenomic sequencing, DNA from separate depth samples was pooled in equimolar

134 concentrations. Paired-end metagenomic sequencing with 2x300bp sequence chemistry was 135 performed with Miseq reagent kit v3 on Illumina Miseq platform (San Diego, California, USA) 136 according to manufacturer's instructions at the Microbiology Department of Radboud University, 137 Nijmegen. 
140 Paired end reads were processed with the Mothur v.1.36.1 software following the standard

141 operation procedure (MySeq SOP) instructions (Kozich et al. 2013). The length of overlapped

142 sequences was filtered for 400-500 base pairs (bp). Chimeric sequences were removed with the

143 UCHIME algorithm (Edgar et al. 2011). Sequences were clustered into operational taxonomic 144 units (OTU) with a 97\% identity cut-off and classified using the SILVA 16S rRNA gene non145 redundant reference database (version 123, SSURef123NR99) and the Bayesian classifier 146 ('wang') (Pruesse et al. 2007). After quality trimming, chimera removal and normalization 147 ("subsampling” in Mothur) of data, each sample contained 5,000 sequences for bacteria and 148 2,000 sequences for archaea. Samples with fewer sequences were excluded from the analysis.

149 Statistical analysis was performed in R (https://www.r-project.org/) (R Development Core 150 Team, 2013) with OTU tables obtained in Mothur using the package Vegan (Oksanen et al. 151 2018). Data visualization was performed in Rstudio (RStudio Team 2015) using the package 152 ggplot2 (Wickham 2016). The R package “OTUtable” was used to merge identical taxonomic 153 groups classified as different OTUs in Mothur (Linz et al. 2017).

155 Metagenome analysis: assembly, binning, annotation

156 Sequencing data obtained from the sediment sample described in this study were analyzed 157 together with data obtained from incubation samples which are part of another study (data not 158 shown).

159 Quality-trimming, sequencing adapter removal and contaminant filtering of Illumina paired-end 160 sequencing reads was performed using BBDuk (BBTools suite version 37.17) (Bushnell), 161 yielding 97,703,456 reads. Processed reads were co-assembled using MEGAHIT v1.1.1-2 (Li et 162 al. 2015; Li et al. 2016) using the "meta-sensitive” preset. MEGAHIT iteratively assembled the 163 metagenome using k-mers of length 21, 29, 39, 59, 79, 99, 119, 141. Reads were mapped back to 
164 the assembled metagenome for each sample separately using Burrows-Wheeler Aligner 0.7.15 165 (Li and Durbin 2010) (BWA), employing the “mem” algorithm. The sequence mapping files were processed using SAMtools 1.6 ( $\mathrm{Li}$ et al. 2009). Metagenome binning was performed for 167 contigs greater than 2,000 bp. To optimize binning results, four different binning algorithms were used: COCACOLA (Lu et al. 2017), CONCOCT (Alneberg et al. 2014), MaxBin 2.0 2.2.3 (Wu et al. 2016) and MetaBAT 2 2.10.2 (Kang et al. 2015). The four bin sets were supplied to DAS

170 Tool 1.0 (Sieber et al. 2018) for consensus binning to obtain the final bins. The quality of the

171 genome bins was assessed through a single-copy marker gene analysis using CheckM 1.0.7

172 (Parks et al. 2015). A coarse taxonomic classification of the genome bins was performed using 173 CheckM and further refined by placing bins in a phylogenetic tree using the UBCG pipeline for 174 phylogenomic tree reconstruction ( $\mathrm{Na}$ et al. 2018). Annotation and biomarker detection was performed with KEGG automatic annotation server with bit score threshold of 100 (Moriya et al. 2007) and the Microbial Annotation and Analysis Platform of MicroScope (MAGE) (Vallenet et

177 al. 2006). All sequencing data obtained for this project were submitted to the GenBank under the 178 BioProject PRJNA511814. The metagenome originating from the in situ sediment in the 179 methanic Fe-rich zone at site NB8 described in this study is designated as sample BS5 180 (BioSample SAMN10644131).

\section{Metagenome analysis: mcrA biomarker analysis}

183 Functional biomarker analysis was performed as described previously (Lüke et al. 2016; Rasigraf 184 et al. 2017). Following the procedures described in Lüke et al. 2017, metagenome data for the in 185 situ sediment sample were quality trimmed with CLC Genomics Workbench 9.5.3 software using 186 the following settings: quality score limit 0.01 (Q20), maximum number of ambiguous base pairs 
Functional biomarkers were identified with blastx (release 2.4.0) using manually curated functional gene databases following the procedure described previously. Amino acid sequence data were aligned in ARB (Ludwig et al. 2004) and used for building an alternative classification taxonomy in MEGAN 5.11.3 based on manually curated mcrA gene database (Huson et al. 2007).

Curated functional gene reads were re-blasted with a database file adapted for alternative taxonomic classification in MEGAN. Blast output was then imported into MEGAN and

194 visualized for quantitative analysis. In total 288 mcrA gene reads were extracted from the metagenome. Quantified data were visualized with the R statistical package ggplot2.

196 For quantitative comparison, the analyzed gene reads were normalized to metagenome size and average gene length according to the following formula: normalized read count $=$ (gene read count*1,000,000,000)/(total metagenome read count*average gene length [nt]).

For SSU rRNA quantification, raw reads were mapped to SILVA database (release 128) in CLC

Genomics Workbench with the following settings: match score 1, mismatch cost 2, insertion cost

3, deletion cost 3 , length fraction 0.5 , similarity fraction 0.8 . Mapped reads were extracted and submitted to SILVAngs online analysis pipeline (www.arb-silva.de/ngs/).

Results and Discussion

\section{Geochemistry of sites N10, NB8 and US5B}

207 Porewater profiles revealed the presence of a shallow SMTZ at all three sites (Figure 2). At site $208 \mathrm{~N} 10$, the SMTZ is located at a depth of about 25-35 cm. At this site, $\mathrm{CH}_{4}$ and $\mathrm{H}_{2} \mathrm{~S}$ concentrations 209 in the porewater were very low. At sites NB8 and US5B, in contrast, the SMTZ was located at 210 depths of about 20-25 cm and 4-9 cm, respectively, and distinct maxima in $\mathrm{H}_{2} \mathrm{~S}$ was observed 
$0.5 \mathrm{mM}$ at site N10 to 1.5 and $3.0 \mathrm{mM}$ at sites NB8 and US5B, respectively. All sediments were

213 rich in dissolved $\mathrm{Fe}^{2+}$, with concentrations increasing in the sequence N10, NB8 and US5B below

214 the SMTZ (Figure 2). This spatial trend was in accordance with the observed 10-fold increase in

215 sediment accumulation rates and corresponding increased input of organic matter with distance

216 from the coast.

217

218 Sediment microbial diversity in the Bothnian Sea

219 Bothnian Sea vertical sediment profiles were analyzed for their bacterial and archaeal populations 220 at sites N10, NB8 and US5B. Results are presented in Figures 3 and 4.

\section{Archaeal 16S rRNA gene distribution in the Bothnian Sea sediments}

223 The vertical distribution of archaeal 16S rRNA gene sequences at all three sites over the sediment

224 profile is shown in Figure 3. The results revealed that archaeal communities were more similar 225 between the neighboring coastal sites N10 and NB8, than to the offshore site US5B. Despite the 226 very similar geochemical profiles at sites NB8 and US5B, the communities were significantly 227 different. Non-metric multidimensional scaling (nMDS) analysis performed on the archaeal 228 species abundances from all sites revealed a clear separation as seen in Figure 5 (B).

229 At all sites, upper sediment microbial communities were distinct from the ones at greater depth.

230 This shift in relative species abundances could be explained by the rapid decrease in available 231 electron acceptors, in particular $\mathrm{SO}_{4}{ }^{2-}$, and the increase of dissolved $\mathrm{Fe}$ and $\mathrm{CH}_{4}$ with depth. 232 When comparing the archaeal community at different depths in the sediment, a similarity was 233 observed for the upper sediment layer $(4-18 \mathrm{~cm})$ of site NB8 with the total profile of site N10. 
234 Since the upper sediment layer of site NB8 was characterized by a similar geochemistry as the

235 whole profile of site N10, the observed similarity might indicate that the local microbial 236 community was adapted to the prevailing environmental conditions.

237 At all sites, the upper $\mathrm{SO}_{4}{ }^{2-}$ containing sediment zone was dominated by Thaumarchaeota Marine 238 Group-I (MG-I). Although their relative abundance decreased with depth, they still could be 239 detected throughout the whole sediment profile at each site. MG-I have previously been shown to 240 be ubiquitous in terrestrial and marine environments in which they are assumed to be involved in 241 aerobic ammonia oxidation (Pester et al. 2011). However, several recent studies have detected 242 genetic signatures of MG-I in deeper anaerobic sediment layers where an aerobic lifestyle is not 243 likely (Rasigraf et al. 2017; and references therein). Some members of MG-I have been shown to 244 use organic $\mathrm{N}$ compounds for growth, without possessing the aerobic ammonia oxidizing enzyme 245 complex and the ability for ammonia oxidation (Weber et al. 2015).

246 Methanotrophic archaea assigned to the ANME-2a/b clade were the most dominant community 247 member of Euryarchaeota and were detected at all analyzed sites. No other ANME clades could 248 be detected. Their relative abundance peaked at the putative SMTZ zone (characterized by 249 measurable porewater sulfide content). Below the SMTZ, ANME 16S rRNA biomarker showed a 250 more scattered distribution. The ANME-2a/b archaeal clade has been detected in many marine 251 and brackish sediments, including different parts of the Baltic Sea (Treude et al. 2005). However, 252 some studies have shown its preference for shallow sediment depths with low $\mathrm{CH}_{4}$ and $\mathrm{H}_{2} \mathrm{~S}$ 253 concentrations (Roalkvam et al. 2012; Roalkvam et al. 2011). Such conditions are also found in 254 the Bothnian Sea, where the salinity of the overlying water and $\mathrm{H}_{2} \mathrm{~S}$ concentrations in the 255 sediments are relatively low. Despite their central role in sulfur cycling, ANME-2a have also 256 been linked to the oxidation of $\mathrm{CH}_{4}$ in the absence of $\mathrm{SO}_{4}{ }^{2-}$ by a direct electron transfer onto 257 artificial shuttles (McGlynn et al. 2015; Scheller et al. 2016). Whether the Bothnian Sea ANME-2 
organisms are able to use Fe oxides as an electron acceptor has not been shown so far. Previous research has indicated that Fe oxides stimulate $\mathrm{CH}_{4}$ oxidation in methanic sediments at site US5B

260 (Egger et al. 2015b).

261 Other abundant archaeal groups comprised Bathyarchaeota, Woesearchaeota and 262 Thaumarchaeota Group C3 (G-C3). Both, Bathyarchaeota and Thaumarchaeota G-C3 were 263 relatively less abundant at US5B ranging between 1-9\% and 1-2\% of total archaeal 16S rRNA 264 gene reads, respectively. Both groups were most prevalent in sediment layers above the SMTZ at NB8 (11-26\% of all archaeal 16S rRNA reads for Bathyarchaeota and 7-32\% for 266 Thaumarchaeota G-C3) and throughout the whole profile of N10 (11-33\% for Bathyarchaeota 267 and 13-29\% for Thaumarchaeota G-C3). Differences in sedimentation rates and quality of 268 deposited organic matter which would differ between coastal and offshore sites, would both 269 affect the degradation dynamics and intermediary metabolites. Thus, the prevalence of both 270 groups could reflect the quality of degradable/fermentable organic matter in the same ecosystem 271 such as the Bothnian Sea. For Bathyarchaeota several MAGs have been analyzed recently. Some

272 studies found genomic indications for possible methylotrophic methanogenesis or anaerobic 273 methanotrophy (Evans et al. 2015; Harris et al. 2018), others speculated on involvement in 274 detrital protein degradation, fermentative acetate production and no capacity for methanogenesis 275 (He et al. 2016; Lazar et al. 2016; Lloyd et al. 2013). Thaumarchaeota G-C3 16S rRNA gene 276 sequences have been detected previously in a variety of terrestrial and marine environments

277 (Hugoni et al. 2015; Na et al. 2015; Zeng et al. 2017). Their role remains somehow enigmatic 278 since no enrichments or genomic sequences are available yet. Some members have been shown, 279 however, to be involved in acetate consumption in $\mathrm{SO}_{4}{ }^{2-}$-reducing marine and estuarine 280 sediments (Na et al. 2015; Webster et al. 2010). 
At all sites, a significant fraction of archaeal reads could not be classified based on the database

282 we used (SILVA release 123). For the deeper layers of US5B, this fraction ranged from 2 to $22 \%$

283 of the total archaeal 16S rRNA gene reads. However, the analysis of MAGs obtained from the

284 methanic zone from site NB8 indicated that at least part of those unclassified archaea belonged to

285 the newly described phyla Thorarchaeota and Lokiarchaeota. Based on the previously published

286 results, Thorarchaeota have been discussed to be involved in acetate production and sulfur

287 cycling by thiosulfate/elemental sulfur reduction (Seitz et al. 2016).

288 The distribution of Woesearchaeota at NB8 followed that of Bathyarchaeota and

289 Thaumarchaeota G-C3. The highest relative abundance was observed above the SMTZ with 5-

$29014 \%$ of total archaeal 16S rRNA gene reads. The abundance decreased below 1\% max below the

291 SMTZ. At US5B, the distribution of Woesearchaeota 16S rRNA gene reads was more even over

292 the sediment depth profile with abundances ranging between 1-9\% of total reads. At N10,

293 Woesearchaeota were also more prevalent in the upper sediment layers above $8 \mathrm{~cm}$ with

294 abundances reaching up to $16 \%$ of total reads, however they were also present throughout the

295 whole core with 1-5\% of total reads. The phylum Woesearchaeota was proposed in 2015 when

296 first bins from environmental metagenomes were analyzed (Castelle et al. 2015). Small genomes

297 and incomplete gene sets necessary for glycolysis, pentose phosphate pathway and pyruvate

298 metabolism were discussed to be indicators for a symbiotic or parasitic lifestyle (Castelle et al.

299 2015). No woesearchaeal metagenomic bins could be retrieved from the analyzed depth at site

300 NB8. This could be explained by a relatively low abundance of 16S RNA genes of

301 Woesearchaeota in deeper layers of NB8 pointing to their low importance in those sediments.

302 Most abundant known methanogens from the phylum Euryarchaeota were represented by

303 families Methanosaetaceae, Methanosarcinaceae, Methanoregulaceae and

304 Methanobacteriaceae. The lowest proportional abundance of all methanogens was detected in 
SMTZ sediment layers. Methanosaetaceae were more prevalent in deeper layers of all sediment profiles with lowest numbers detected at N10. Their relative abundance reached $4 \%$ of total archaeal reads at N10, 16\% at US5B and 13\% at NB8. Methanosarcinaceae were present at all sites, with lowest numbers at N10 (2\% max of total archaeal reads). Their distribution below the SMTZ at NB8 was rather scattered ranging between $1-13 \%$ of total archaeal reads. Higher abundances of Methanosarcinaceae correlated with lower abundances of ANME reads. At US5B,

311 the abundance of Methanosarcinaceae reads ranged between 1-6\% and was the highest in the deepest analyzed depth at 52.5-55 cm. This depth was also characterized by the highest observed proportion of Methanosaetaceae gene reads. Methanoregulaceae were more prevalent in sediment layers below the SMTZ at both US5B and NB8. At N10, their distribution correlated well with that of Methanosaetaceae. Relative abundances of total archaeal reads reached $8 \%$ at US5B, 7\% at NB8 and 11\% at N10. The distribution of Methanobacteriaceae was opposite to that of other methanogens. Highest abundances were detected above the SMTZ at NB8 with 4\% max of total archaeal reads. Below the SMTZ, the abundance never exceeded $1 \%$ of total archaeal reads. At US5B, Methanobacteriaceae reads were below $1 \%$ throughout the sediment core. Also at N10, the highest abundance with $6 \%$ of total archaeal reads was observed in the upper most layer of $4-5 \mathrm{~cm}$. In the deeper profile of N10, their abundance did not exceed $1 \%$ of total reads. Previous research has shown that Methanosaetaceae methanogens are strict 323 acetotrophs and adapted to low acetate concentrations (Jetten et al. 1992). Low concentrations 324 would be indicative of either low production or high turnover of acetate in Bothnian Sea 325 sediments. In contrast, Methanosarcinaceae methanogens are generalists by being able to utilize a variety of substrates for $\mathrm{CH}_{4}$ production, but appear to possess lower affinities to acetate (Jetten 327 et al. 1992; Liu and Whitman 2008). Both Methanobacteriaceae and Methanoregulaceae have 
330 been shown to use methanol with $\mathrm{H}_{2}$ (Fricke et al. 2006). Beside acetate, $\mathrm{H}_{2}$ is a major by-product

331 of various fermentative processes and would be available to methanogens and other

332 hydrogenotrophs in these sediments. Thus, the presence of all detected methanogens indicates a

333 niche separation by availability of different substrates or/and fluctuations in acetate/ $\mathrm{H}_{2}$

334 concentrations.

\section{Bacterial 16S rRNA gene distribution in the Bothnian Sea sediments}

337 Similar to the archaeal communities, the bacterial 16S rRNA gene distribution between the 338 coastal and central basin was significantly different (Figure 4). Both, N10 and NB8 were more 339 similar to each other than NB8 and US5B (nMDS, Figure 5 (A)).

340 Particularly, the top sediment layer revealed substantial differences between the sites. At US5B, 341 an apparent population of aerobic $\mathrm{CH}_{4}$ oxidizing bacteria (MOB) represented by 342 Methylococcaceae was detected (6\% of total bacterial reads). In contrast, this group was 343 significantly lower in abundance at coastal sites with only few detected sequences. An 344 enrichment of this group close to the sediment surface would point to a less efficient $\mathrm{CH}_{4}$ 345 removal in deeper anoxic layers at US5B, particularly the SMTZ where most of the $\mathrm{CH}_{4}$ would 346 be oxidized by ANME. $\mathrm{CH}_{4}$ that is not consumed in the SMTZ diffuses towards the sediment 347 surface and fuels aerobic methanotrophic communities. The absence of surface sediment MOB 348 communities at the coastal sites could be a result of either more efficient removal within the 349 SMTZ (NB8) or a lower production by methanogens in deeper layers as seen at site N10.

350 The genus Spirochaetales was relatively more abundant at US5B, reaching a contribution of $12 \%$ 351 in the deeper part of the profile. At both coastal sites, the abundances did not exceed $4 \%$. In 352 contrast, at both coastal sites Anaerolineales and Bacteroidetes_VadinHA17 were relatively more 
353 abundant than at US5B. All three groups, Anaerolineales, Bacteroidetes_VadinHA17 and

354 Spirochaetales belong to an anaerobic core community involved in different fermentation

355 pathways. The metabolic potential of Anaerolineales, reconstructed from several sequenced

356 genomes and cultured representatives, points to a strictly anaerobic chemo-organotrophic lifestyle

357 (Hug et al. 2013; Yamada et al. 2006). Members of the genus Spirochaeta have been shown

358 previously to be an integral part of anoxic sediment communities (Breznak and Warnecke 2008;

359 Shivani et al. 2015; and references therein). They are free-living, chemo-organotrophic

360 facultative or obligate anaerobes capable of production of various fermentation products

361 including acetate, ethanol, $\mathrm{H}_{2}$ and $\mathrm{CO}_{2}$ (Breznak and Warnecke 2008; Miyazaki et al. 2014).

362 Bacteroidetes_VadinHA17 is an abundant member of sediment communities and has been

363 discussed to be involved in degradation of organic matter (Bolhuis et al. 2014; Harrison et al.

364 2016). The observed differences in abundance of these three groups indicated that organic

365 metabolite flows are different between coastal and central-basin sediments and could probably be

366 explained by the quality of organic matter.

367 Another significant group of 16S rRNA gene sequences detected at all sites in different

368 proportions was assigned to Xanthomonadales. Their sequences were already detected in high

369 abundance at site US5B in our previous study (Rasigraf et al. 2017) and they are here shown to

370 be ubiquitous in the Bothnian Sea sediments among analyzed depths. Sequences belonging to

371 Xanthomonadales have previously been observed to be abundant in marine and brackish

372 sediments (Dyksma et al. 2016; Mußmann et al. 2017). Based on the genomic information, they

373 have been predicted to play an important in role $\mathrm{S}$ and $\mathrm{N}$ cycles by employing either

374 chemolithoautotrophic or -heterotrophic lifestyle (Mußmann et al. 2017). Thus,

375 Xanthomonadales may be a major contributor to dark $\mathrm{CO}_{2}$ fixation in marine sediments (Dyksma

376 et al. 2016). 
Atribacteria (formerly known as candidate divisions “OP9” and “JS1”) increased in relative

378 abundance in the deeper part of the N10 sediment and reached up to $10 \%$ of the total bacterial

379 16S rRNA gene reads. At, NB8 and US5B, their abundance did not exceed 3\% of total bacterial

380 reads. Atribacteria have been shown previously to be abundant in anaerobic low energy

381 environments (Newberry et al. 2004). Based on the available genome information, they appear to

382 perform either primary fermentation, secondary fermentation or syntrophy for catabolism (Carr et

383 al. 2015; Nobu et al. 2016). Their sequences have also been detected in Fe- and $\mathrm{CH}_{4}$-rich marine

384 sediments of the Helgoland area in the North Sea (Oni et al. 2015a). There, their abundance

385 strongly correlated with concentrations of dissolved $\mathrm{Fe}$ and $\mathrm{CH}_{4}$, and their possible involvement

386 in Fe-dependent AOM together with members of Methanosaetaceae and the ANME-3 clade was

387 suggested (Oni et al. 2015a). Other studies have also reported a regular occurrence of

388 Atribacteria in sediments dominated by $\mathrm{SO}_{4}{ }^{2-}$-dependent AOM (Harrison et al. 2009). Carr et al.

2015 identified a strong correlation between dissolved $\mathrm{CH}_{4}$ profiles and abundance of

390 Atribacteria in Arctic marine sediments. The observed correlation was suggested to be based on

391 metabolic co-operation with methanogens which would scavenge fermentation products of

392 Atribacteria, primarily acetate (Carr et al. 2015). The conditions at site N10 seem to favor the

393 presence of Atribacteria in contrast to putative Spirochaetales fermenters at site US5B.

394 Desulfobacterales were high in abundance at all sites. Members of Desulfobacterales include 395 many characterized sulfate reducing bacteria (SRB) which use $\mathrm{SO}_{4}{ }^{2-}$ and other sulfur compounds 396 as terminal electron acceptors and a variety of fermentation products as electron donors (Pfennig 397 et al. 1981). At NB8 and US5B, a top to bottom gradient could be observed with highest 398 abundances coinciding with the SMTZ. At N10, no apparent gradient could be observed and their 399 16S rRNA genes were distributed rather evenly over the whole sediment profile. At this site the $400 \mathrm{SO}_{4}{ }^{2-}$ penetration depth is also deeper than at NB8 and US5B (Figure 2). Desulfobacterales are 
401 often detected in marine sediments where $\mathrm{SO}_{4}{ }^{2-}$ and $\mathrm{CH}_{4}$ are present (Leloup et al. 2007; Ruff et 402 al. 2015). Some members of the Desulfobacterales are frequently observed partners in 403 ANME/SRB consortia, where they perform $\mathrm{SO}_{4}{ }^{2-}$ reduction and scavenge the reducing 404 equivalents from ANME (Schreiber et al. 2010). Different ANME clades prefer certain SRB 405 groups as partners, and it has been shown previously that ANME-2a are often detected together 406 with SEEP-SRB1a - a clade belonging to Desulfobacterales (Schreiber et al. 2010). Our results 407 are in line with previously published studies as the dominant ANME clade observed so far at all 408 sites in the Bothnian Sea sediment belonged to ANME-2a. As expected, their highest abundance 409 was observed in the zone where $\mathrm{SO}_{4}{ }^{2-}$ was detectable and where $\mathrm{SO}_{4}{ }^{2-}$ reduction was expected to 410 occur. However, despite $\mathrm{SO}_{4}{ }^{2-}$ being under the detection limit $(75 \mu \mathrm{M})$ below the SMTZ at NB8 411 and US5B, a zone where Fe-dependent $\mathrm{CH}_{4}$ oxidation was postulated to occur (Egger et al. 412 2015b), the presence of SRB was indicative of either a presence of a high flux of oxidized S413 species or SRB performing other types of metabolisms (e.g. fermentation). Previous research has 414 shown that SRB can switch from the respiratory metabolism to fermentation when suitable 415 electron acceptors are not available (Plugge et al. 2011). In such situation, a cooperation with $\mathrm{H}_{2}-$ 416 scavenging methanogens is feasible (Plugge et al. 2011). Thus, a sudden introduction of $\mathrm{SO}_{4}{ }^{2-}$ 417 could potentially activate their $\mathrm{SO}_{4}{ }^{2-}$ metabolism.

418 Verrucomicrobiales was abundant at both coastal sites but not in the central basin site US5B. Its 419 distribution showed a strong gradient with highest numbers (up to 11\% at NB8) near the 420 sediment-water interface and a rapid decline within the sediment column. This change with depth 421 points to an adaptation to high redox potential and possibly an aerobic/denitrifying lifestyle of 422 dominant members making up the bulk of detected Verrucomicrobiales sequences. 423 Verrucomicrobia have been previously shown to be abundant in marine water columns and 424 sediments and to be mostly involved in polysaccharide degradation (Cardman et al. 2014; 
425 Martinez-Garcia et al. 2012). A similar distribution of Verrucomicrobia sequences was observed

426 previously and was linked to degradation of fresh algal biomass in surface sediments of the North

427 Sea (Oni et al. 2015b). Thus, based on previously available data, Verrucomicrobiales would

428 belong to a community of primary degraders and possibly provide substrates for anaerobic

429 fermentative communities.

430 Sequences belonging to Flavobacteriales were detected in high abundance at all sites. Highest 431 abundances were observed within the $\mathrm{SO}_{4}{ }^{2-}$ penetration zone and $\mathrm{SMTZ}$, similar to that of 432 Desulfobacterales. At NB8, their abundance reached $10 \%$ of total bacterial reads within the 433 SMTZ. At N10, their numbers slightly declined from top to bottom of the core with depth in the 434 sediment, but did not exceed the maximum of 6\%. Interestingly, at US5B, the Flavobacteriales 435 sequence distribution initially followed that of both coastal sites with higher numbers at the top 436 (6\%) and declining towards $2 \%$ below the SMTZ, but the relative abundance started to increase 437 again at the bottom of the sediment profile reaching up to $10 \%$ in the lowest analyzed depth of 438 52.5-55 cm. Interestingly, members of the Flavobacteriales were detected previously in an 439 anaerobic methanotrophic enrichment originating from marine sediments (Jagersma et al. 2009).

440 In active AOM cultures dominated by an ANME-2a archaeon, Flavobacteriales and 441 Desulfobacterales together made up the bulk of the total bacterial sequences (Jagersma et al. 442 2009). Their metabolic role in that enrichment culture remained unclear, and possible 443 involvement in S-compound transformations was discussed (Jagersma et al. 2009).

444 Another abundant group of bacteria detected at NB8 was assigned to the Planctomycetales. Their 445 sequence abundance reached 6\% and remained fairly constant throughout the sediment profile by 446 minor variations between 3-6\%. At N10, highest percentages of the total community were 447 observed in the top $3 \mathrm{~cm}$ (6-7\%), below which the population stayed at ca. 3\% of the total 448 bacterial reads. By further zooming in to a genus level, most reads were found to be assigned to 
450 lineages have been previously detected, described and isolated from $\mathrm{Fe}$ - and $\mathrm{CH}_{4}$-rich marine

451 sediments (Storesund and Øvreås 2013; Winkelmann et al. 2010). They were shown to be

452 involved in sugars and complex carbohydrate degradation, some were speculated to be involved

453 in either $\mathrm{Fe}-$ or $\mathrm{CH}_{4}$ oxidation (Storesund and Øvreås 2013). Thus, the most abundant

454 Planctomycetales residing in the Bothnian Sea sediment are most likely involved in the

455 hydrolysis and degradation of complex organic matter.

457 Metagenomic analysis of the Fe-rich methanic sediment at site NB8 in the Bothnian Sea

458 Metagenome assembly and binning of sediment samples at the coastal site NB8 resulted in a 459 retrieval of 53 bacterial and 11 archaeal genomic bins with variable degree of completeness 460 (Supplementary Table 1, only bins with $>20 \%$ completeness, contamination level $<10 \%$ and $461>0.1 \%$ proportion of total sequenced community were analyzed). In line with the abundance 462 frequency in the 16S rRNA amplicon sequencing data, genome bins could be obtained for most 463 abundant bacterial lineages including Spirochaeta, Aminicenantes, Atribacteria, Chloroflexi, 464 Actinobacteria, Bacteroidetes, Gemmatimonadales, Nitrospira, Planctomycetes, Parcubacteria, $465 \alpha-, \beta-, \gamma$-, $\delta$-Proteobacteria and archaeal lineages including Thaumarchaeota, Bathyarchaeota, 466 Thorarchaeota, Methanomassiliicoccales, Methanosaeta, Methanosarcina, ANME. We analyzed 467 all bins and draft genomes for the presence of marker genes involved in fermentation, 468 autotrophy/acetogenesis, methanogenesis/-trophy and respiratory $\mathrm{N}$ and S cycles (Figures 6 and 469 7, Supplementary Table 2). 
472 In anaerobic sediments, Fe and manganese (Mn) oxides can undergo abiotic reactions with $\mathrm{H}_{2} \mathrm{~S}$

473 and lead to its oxidation to either partially reduced sulfur species (PRSS, comprising thiosulfate,

474 polysulfide, tetrathionate, sulfite and elemental sulfur) or completely to $\mathrm{SO}_{4}{ }^{2-}$ (Zopfi et al. 2004).

475 Anoxic Bothnian Sea sediments below the SMTZ have been shown to contain high 476 concentrations of Fe oxides which consist for $>50 \%$ of ferric (oxy)hydroxide (Egger et al. 2015a;

477 Lenstra et al. 2018; Slomp et al. 2013). Thus, any free $\mathrm{H}_{2} \mathrm{~S}$ is likely to react fast either with the Fe 478 oxides or precipitate as $\mathrm{FeS}$ with $\mathrm{Fe}^{2+}$. Partial oxidation of free $\mathrm{H}_{2} \mathrm{~S}$ with $\mathrm{Fe}$ oxides has been 479 suggested to lead to formation of $\mathrm{SO}_{4}{ }^{2-}$ and thiosulfate (or other PRSS) which would act as an 480 electron acceptor source for organisms which would reduce the PRSS and $\mathrm{SO}_{4}{ }^{2-}$ with donors such 481 as acetate or $\mathrm{H}_{2}$ back to $\mathrm{H}_{2} \mathrm{~S}$ (Zopfi et al. 2004). This cycle has been described as cryptic S cycle 482 in marine anoxic sediments (Brunner et al. 2016; Holmkvist et al. 2011). We analyzed the 483 presence of functional gene biomarkers involved in reductive processes such as 484 thiosulfate/polysulfide reductase (Phs/Psr), sulfhydrogenase (Hyd), tetrathionate reductase (Ttr), 485 sulfite reductase (Asr), dimethyl sulphoxide (DMSO) reductase (Dms), adenylyl-sulfate reductase 486 (Apr)/dissimilatory (bi)sulfite reductase (Dsr). The latter, Apr/Dsr complex, was also shown to 487 catalyze the reverse reaction of $\mathrm{H}_{2} \mathrm{~S}$ oxidation to $\mathrm{SO}_{4}{ }^{2-}$ in some Proteobacteria and Chlorobi 488 (Ghosh and Dam 2009; Müller et al. 2015).

489 In general, genes potentially involved in PRSS transformations were detected in most of the 490 retrieved bacterial MAGs indicating a potential for an active S cycle in the methanic zone below 491 the SMTZ. Among archaeal MAGs, the most widespread PRSS metabolism biomarkers encoded 492 sulfhydrogenase-like proteins. However, genes encoding all four subunits (HydABDG) were only 493 detected in bins assigned to Thorarchaeota, corroborating recent findings about these recently 494 characterized organisms (Seitz et al. 2016). Other bacterial and archaeal MAGs mostly only 495 encoded one or two of the four Hyd-like comprising subunits. 
496 Biomarkers for dissimilatory $\mathrm{SO}_{4}{ }^{2-}$ reduction to $\mathrm{H}_{2} \mathrm{~S}$ (Apr/Dsr) were detected in six bacterial

497 MAGs. Apr without the presence of Dsr was found in Bacteroidales and 498 Xanthomonadales/Chromatiales, while Dsr without Apr was detected one Aminicenantes MAG.

499 Both biomarkers were detected in Syntrophobacterales and Gemmatimonadales. Many members

500 of the Syntrophobacterales order are $\mathrm{SO}_{4}{ }^{2-}$ reducers frequently detected in anaerobic $\mathrm{SO}_{4}{ }^{2-}-$

501 containing sediments (Plugge et al. 2011). The finding of one Gemmatimonadales genomes also

502 containing both Apr and Dsr encoding genes was more surprising. Recently, similar observations

503 were reported for Gemmatimonadales MAGs obtained from estuarine sediments (Baker et al.

504 2015), however no $\mathrm{SO}_{4}{ }^{2-}$ reducers have been described so far from this group. Thus, these

505 previously unknown potential SRB might be widespread in estuarine, marine and brackish

506 sediments and their role in $\mathrm{SO}_{4}{ }^{2-}$ reduction might have been overlooked in the past.

507 The detected Apr in one the Xanthomonadales/Chromatiales MAGs indicated potential

508 involvement in sulfite oxidation. Members of Chromatiales and particularly

509 Ectothiorhodospiraceae family, have been frequently detected in marine anoxic sediments and

510 were shown to employ a chemolithoautrophic lifestyle of either Fe- or reduced S compound

511 oxidation (Dyksma et al. 2016; Hallberg et al. 2011). The detection of a phosphoribulokinase

512 (Prk) in one of the MAGs classified into this group further pointed to some of them likely being

513 autotrophs.

514 Interestingly, homologues of a desulfoviridin-type dissimilatory sulfite reductase were detected in

515 MAGs classified as ANME-2a and Lokiarchaeota. This type of a sulfite reductase is involved in

516 an energy-yielding reduction of sulfite to $\mathrm{H}_{2} \mathrm{~S}$. This finding is particularly interesting in the view

517 of anaerobic $\mathrm{CH}_{4}$ oxidation potential in these sediments. ANME are typically associated with

518 SRB in order to perform AOM, in which the bacterial partner would perform the reduction of

$519 \mathrm{SO}_{4}{ }^{2-}$ or PRSS to $\mathrm{H}_{2} \mathrm{~S}$ (Knittel and Boetius 2009). However, this finding indicates the potential of 
520 Bothnian Sea ANME to perform the reduction of sulfite intrinsically. The ability of some ANME

521 to reduce sulfur species has been observed earlier (Milucka et al. 2012).

522 Several core community members of putative fermenters including Anaerolineales,

523 Bacteroidales, Atribacteria and Aminicenantes also encoded gene homologues for enzymes

524 involved in PRSS transformations. This indicated flexible metabolic strategies switching between

525 PRSS respiration and fermentations depending on environmental conditions.

526 Also DMSO reductase-like encoding genes were detected in several retrieved MAGs. DMSO is a

527 common metabolite in marine and brackish ecosystems were it is produced by microalgae,

528 phytoplankton and angiosperms as osmoprotectant (López and Duarte 2004). DMSO can then be

529 used as electron acceptor under anaerobic conditions which results in the production of dimethyl

530 sulfide. Among others, one MAG assigned to Aminicenantes, which is based on metagenome

531 data the most abundant bacterial group in the investigated sediment layer (Supplementary Table

532 1), contained Dms-like encoding genes. Thus, potential for reductive respiratory S cycle

533 metabolisms seems widespread in core community bacterial taxa.

534 In the presence of energetically more favorable electron acceptors like $\mathrm{NO}_{3}{ }^{-}$or $\mathrm{Mn}^{4+}$, reduced

535 sulfur compounds can be completely oxidized to $\mathrm{SO}_{4}^{2-}$ (Zopfi et al. 2004). This process would

536 represent a source of $\mathrm{SO}_{4}{ }^{2-}$ and thus electron acceptor for SRB. The analyzed biomarkers for

537 PRSS and $\mathrm{H}_{2} \mathrm{~S}$ oxidation included sulfur dioxygenase (Sdo), sulfur oxidizing multi-enzyme

538 system (Sox), sulfide:quinone oxidoreductase (Sqr) and sulfite oxidase (Soe). In general,

539 homologues of genes encoding enzyme subunits involved in oxidative processes in the S cycle

540 were less widespread than those involved in PRSS reduction. This redundancy in the potential for

541 oxidative processes could be further explained with the lack or shortage of electron acceptors in

542 this sediment layer. Thus, the residing microbial community would over time lose the ability for

543 PRSS oxidation. 
544 The results of respiratory S cycle analysis indicated the potential for PRSS reductive processes in

545 many analyzed MAGs while that for oxidative ones was scarcer. These findings point to a

546 possibility of a shorter operational $\mathrm{S}$ cycle where the abiotic oxidation of $\mathrm{H}_{2} \mathrm{~S}$ by the reactive Fe

547 would create a pool of PRSS which would be reduced back to $\mathrm{H}_{2} \mathrm{~S}$.

\section{Respiratory nitrogen $(\mathbf{N})$ cycle}

$550 \mathrm{~N}$ cycle activities have been recently investigated in Öre Estuary sediments (Hellemann et al.

551 2017). Nitrification-denitrification seemed to be the dominant sink for reactive $\mathrm{N}$ in the

552 ecosystem while anaerobic ammonium oxidation (anammox) was not detectable (Hellemann et

553 al. 2017). Several genomic bins obtained within this study contained gene homologues encoding

554 various enzymes catalyzing respiratory $\mathrm{N}$ cycle processes.

555 For the initial step of $\mathrm{NO}_{3}{ }^{-}$reduction, two types of $\mathrm{NO}_{3}{ }^{-}$reduction systems were analyzed: a

556 periplasmic (Nap) and membrane-bound nitrate reductase (Nar). Nar resembles high similarity to

557 nitrite oxidoreductase (Nxr) which catalyzes oxidation of nitrite $\left(\mathrm{NO}_{2}{ }^{-}\right)$to $\mathrm{NO}_{3}{ }^{-}$. Both Nap and

558 Nar exhibited similar abundance among analyzed bacterial taxa. Only two groups,

559 Xanthomonadales/Chromatiales and Gemmatimonadales contained both Nap and Nar. In

560 addition, some Gemmatimonadales MAGs also contained genes encoding for enzymes catalyzing

561 reduction of $\mathrm{NO}_{2}{ }^{-}$to nitric oxide (NO) (NirK) and reduction of nitrous oxide $\left(\mathrm{N}_{2} \mathrm{O}\right)$ to $\mathrm{N}_{2}$ (Nos).

562 Next to a wide spectrum of genes involved in fermentation product metabolism, $\mathrm{SO}_{4}{ }^{2-}$ and PRSS

563 reduction, the order Gemmatimonadales appeared to possess high metabolic diversity.

564 Nxr was only detected in one MAG classified as Nitrospirales, an order which includes many

565 characterized $\mathrm{NO}_{2}{ }^{-}$oxidizers widespread in natural ecosystems (Lücker et al. 2010). Additionally,

566 it also contained a Cu-dependent nitrite reductase (NirK) encoding gene. Possibly, the detected 
Nitrospira organisms could switch between $\mathrm{NO}_{2}{ }^{-}$oxidation and denitrification depending on

568 redox potential and substrate availability.

569 Syntrophobacterales encoded a Nar and cytochrome c nitrite reductase (Nrf), besides the 570 potential for $\mathrm{SO}_{4}{ }^{2-}$ reduction. Previous studies with characterized SRB have shown the preferred 571 use of $\mathrm{NO}_{3}{ }^{-}$as an electron acceptor when available (Krekeler and Cypionka 1995). The capability

572 for DNRA seems to be a common trait among SRB and indicates a flexible metabolism 573 depending on the availability of electron acceptors and a coupling of dissimilatory $\mathrm{N}$ and $\mathrm{S}$

574 cycles. Another recent study showed that SRB Desulfurivibrio alkaliphilus can employ a 575 chemolithotrophic metabolism by $\mathrm{NO}_{3}{ }^{-}$reduction to $\mathrm{NH}_{4}{ }^{+}$and oxidation of $\mathrm{H}_{2} \mathrm{~S}$ to thiosulfate or 576 elemental sulfur (Thorup et al. 2017). Research on partnerships of ANME with different types of 577 SRB has indicated that availability of $\mathrm{NO}_{3}{ }^{-}$may play an important role in the establishment of 578 certain types of ANME/SRB symbioses (Green-Saxena et al. 2014). $\mathrm{NO}_{3}{ }^{-}$was shown to be used 579 as an $\mathrm{N}$ source, however its incorporation into biomass was secondary to $\mathrm{NH}_{4}^{+}$and the authors 580 could not exclude DNRA as a possible mechanism (Green-Saxena et al. 2014).

581 Functionally, dissimilatory $\mathrm{NO}_{3}{ }^{-}$reduction can be decoupled from further steps of $\mathrm{NO}_{2}{ }^{-}$reduction 582 and an organism can excrete $\mathrm{NO}_{2}^{-}$which can be further used as an electron acceptor by other 583 community members. The fate of $\mathrm{NO}_{2}^{-}$then differs depending on genomic potential. It can be 584 either reduced to $\mathrm{NO}$ and then to $\mathrm{N}_{2} \mathrm{O}$ or reduced in one step to $\mathrm{NH}_{4}{ }^{+}$by $\mathrm{Nrf}$. $\mathrm{NO}$ is a toxic and 585 very reactive metabolite which is usually processed by the cell immediately. Thus, we analyzed 586 the presence of NO-forming nitrite reductases (NirK/NirS) in combination with NO reductases 587 (Nor) as one module for denitrification to $\mathrm{N}_{2} \mathrm{O}$. The product of this process is $\mathrm{N}_{2} \mathrm{O}$ which again 588 can be either excreted into the environment or further reduced to $\mathrm{N}_{2} \cdot \mathrm{N}_{2} \mathrm{O}$ reduction can be 589 performed by a different functional group of denitrifiers. Both denitrification modules, to $\mathrm{N}_{2} \mathrm{O}$ 590 and to $\mathrm{N}_{2}$, were spread among the retrieved MAGs indicating functional redundancy and 
591 truncation in metabolic denitrification potential. However, activity measurements performed by

592 Hellemann et al. 2017 revealed that the contribution of $\mathrm{N}_{2} \mathrm{O}$ production to total denitrification in

593 Öre Estuary sediments was below $1 \%$ and was thus negligible. The ratio of $\mathrm{N}_{2} \mathrm{O} / \mathrm{N}_{2}$ as end

594 product of denitrification is influenced by several factors including organic carbon and $\mathrm{NO}_{3}{ }^{-}$

595 loads (Weier et al. 1993). The Öre Estuary is an oligotrophic system which is limited in easy

596 accessible electron donors (Hellemann et al. 2017). However, seasonal changes in the input of

597 organic matter and $\mathrm{N}$ availability might shift the ratio of $\mathrm{N}_{2} \mathrm{O}$ to $\mathrm{N}_{2}$ production in the system.

598 The potential for DNRA was only present in Syntrophobacterales, Gemmatimonadales and

599 Chrysiogenales MAGs. They also possessed marker genes for PRSS transformations, thus DNRA

600 could be driven by electrons derived from the oxidation of $\mathrm{H}_{2} \mathrm{~S}$ or alternatively fermentation

601 products. The activity of either DNRA or denitrification for $\mathrm{NO}_{2}{ }^{-}$reduction would depend on the

602 quality and availability of electron donors in the estuary sediment system.

603 Nitrification potential was assessed by the presence of Amo/Hao encoding genes. Amo/Hao 604 catalyzes the oxidation of ammonia to $\mathrm{NO}_{2}^{-}$, which can then be used by $\mathrm{NO}_{2}^{-}$oxidizers such as 605 Nitrospira for further oxidation to $\mathrm{NO}_{3}^{-}$by an Nxr. Both processes require a potent electron 606 acceptor such as oxygen $\left(\mathrm{O}_{2}\right)$. Two MAGs assigned to putative ammonia oxidizers could be 607 retrieved from the analyzed sediment. One was assigned to Nitrosomonadales, a bacterial order 608 which includes many characterized ammonia oxidizers, and another to archaeal Thaumarchaeota.

609 However, only the Nitrosomonadales MAG contained both Hao and Amo, the thaumarchaeal

610 MAG lacked the genes encoding for Hao/Amo. However, since the latter was only 46\% 611 complete, it is likely that ammonia oxidation pathway encoding genes were not binned into the 612 MAG. Both ammonia oxidizing bacteria (AOB) and archaea (AOA) might be participating in the 613 oxidation of $\mathrm{NH}_{4}{ }^{+}$to $\mathrm{NO}_{2}^{-}$in the coastal Bothnian Sea sediment. It is not clear, however, how $\mathrm{O}_{2}$ 614 would be available for their metabolism in the analyzed depth since air is unlikely to penetrate to 
615 the methanic zone below the SMTZ. It has been shown previously that $\mathrm{O}_{2}$ penetration depths are

616 restricted to the upper centimeter in the Öre Estuary sediments (Hellemann et al. 2017). The

617 presence of aerobic nitrifiers in anoxic environments has been frequently observed in the past and

618 an alternative anaerobic metabolism was discussed as a possible lifestyle strategy (Abeliovich

619 and Vonshak 1992; Schmidt et al. 2002; Weber et al. 2001). Some studies from the 1990s and

620 more recent ones have hypothesized the possibility of nitrification coupled to metal oxide

621 reduction involving, for example, Fe and Mn oxides (Hulth et al. 1999; Luther et al. 1997;

622 Mogollón et al. 2016; Thamdrup and Dalsgaard 2000). An alternative explanation would be a

623 dormant nitrifier community which was preserved at this depth due to fast sedimentation and

624 slow degradation rates.

625 Our results show that even in the complete absence of $\mathrm{O}_{2}$ and despite the activity of alternative

626 anaerobic processes, the analyzed sediment still contains a genetic potential for $\mathrm{O}_{2}$-dependent

627 nitrification.

628

\section{Fermentative metabolism}

630 Fermentative processes are of central importance in sediment ecosystems since anaerobic 631 degradation of deposited organic matter yields a variety of short chain fatty- and carboxylic acids 632 and $\mathrm{H}_{2}$ which can be further used in respiratory processes for the reduction of oxidized N-, S- and 633 Fe species, methanogenesis and homoacetogenesis (Finke et al. 2007). The production and 634 consumption of those organic and inorganic $\left(\mathrm{H}_{2}\right)$ intermediates depends on factors such as 635 sediment $\mathrm{pH}$, temperature, quality of the deposited organic matter and availability of inorganic 636 electron acceptors. These factors are expected to vary depending on seasonality, external input 637 variability, bioturbation and sedimentation rates. Thus, the presence of gene biomarkers only 
638 represents the potential of the system for the analyzed processes and not the actual metabolite 639 flows.

640 In marine and brackish sediments where the $\mathrm{pH}$ is usually between 7 and 7.5, major fermentation

641 products comprise acetate, formate, ethanol, propionate, butyrate, lactate and $\mathrm{H}_{2}$. Acetate is the 642 central metabolite in marine sediments (Shaw and McIntosh 1990). We analyzed the presence of

643 four functional biomarkers involved in acetate metabolism: (ADP-forming) acetate-CoA ligase 644 (Acd), acetate kinase (Ack), acetyl-CoA hydrolase (Ach) and acetyl-CoA synthetase (Acs). 645 Those enzymes can catalyze reactions in both directions which will depend on environmental 646 conditions and the employed metabolism by the organism.

647 In general, most MAGs contained the genes encoding either one of several of the 648 abovementioned enzymes. Acd and Acs were the most widespread acetate metabolism 649 biomarkers among both bacteria and archaea including Thorarchaeota, Bathyarchaeota and 650 Lokiarchaeota. Thus, those archaea could contribute to fermentative acetate production or 651 assimilation in methanic sediments below SMTZ.

652 Formate metabolism was assessed by the presence of pyruvate-formate lyase (Pfl) which 653 catalyzes formate formation from pyruvate, and formate dehydrogenase (Fdh/Fdo) for formate 654 oxidation. Both genes were widely distributed among bacterial and archaeal bins. Many putative 655 fermenters including Spirochaetales, Bacteroidales, Aminicenantes and Atribacteria contained 656 both. Among archaeal MAGs, the potential for acetate and formate turnover was widespread 657 corroborating previous results for Bathyarchaeota and Thorarchaeota being potentially involved 658 in fermentative production of acetate and formate (Lazar et al. 2016; Seitz et al. 2016). The 659 lowest distribution was observed for propionate turnover encoding genes (Prp).

660 The ability for ethanol metabolism which was assessed by the presence of aldehyde and alcohol 661 dehydrogenases (Aldh/Adh/Exa/Frm/Yia/Eut) appeared to be one of the most widespread traits 
among the retrieved bacterial MAGs. This was an indication for ethanol being next to acetate and

663 formate an important metabolite in the analyzed sediment system. Among archaea, however, it 664 was only detected in Bathyarchaeota, Thaumarchaeota and Methanosaeta, indicating their 665 potential involvement in ethanol production/uptake.

666 Lactate metabolism was assessed by the presence of cytochrome- (Lldh/Ldhd) and NAD(P)667 dependent (Ldh) lactate dehydrogenase encoding genes. Several bacterial MAGs possessed 668 lactate utilization biomarkers. In archaea only the highly incomplete MAG assigned to ANME 669 contained an Lldh-like gene. The rest of archaeal bins did not seem to possess capacity for lactate 670 metabolism.

671 The ability for $\mathrm{H}_{2}$ metabolism was assessed by the presence of genes encoding for subunits of 672 various types of hydrogenases. Genes encoding for the following hydrogenase complexes were 673 detected in the analyzed MAGs: bi-directional NAD(H)-dependent [NiFe] hydrogenase (Hox), 674 periplasmic [NiFeSe] hydrogenase (Hya), [Fe] hydrogenase (Hyd), [NiFe] hydrogenases which 675 couple $\mathrm{H}_{2}$ production to formate or $\mathrm{CO}$ oxidation, ferredoxin-dependent bi-directional [NiFe] 676 hydrogenase Ech, [FeFe] hydrogenases mostly involved in $\mathrm{H}_{2}$ production but also oxidation in 677 SRB particularly and F420-non-reducing hydrogenases. Overall, genes encoding hydrogenase 678 subunits or hydrogenase maturation pathways were detected in most of the analyzed bacterial and 679 archaeal MAGs indicating the central importance of $\mathrm{H}_{2}$ in the analyzed sediment ecosystem.

680 Putative bacterial fermenters including Spirochaetales, Bacteroidales, Anaerolineales, 681 Aminicenantes and SRB contained genes encoding several hydrogenase systems indicating an 682 adaptation to ambient fluctuations in metabolite concentrations. One of the Gemmatimonadales 683 MAGs which encoded the whole $\mathrm{SO}_{4}{ }^{2-}$ reduction pathway also contained genes encoding for two 684 types of hydrogenases. Thus, this potential SRB could be utilizing $\mathrm{H}_{2}$ as an electron donor for $685 \mathrm{SO}_{4}{ }^{2-}$ reduction. Similarly, also Syntrophobacterales which encoded the full $\mathrm{SO}_{4}{ }^{2-}$ reduction 
pathway revealed a wide $\mathrm{H}_{2}$ utilization potential via different hydrogenases. In general, all genomes with a Dsr encoded for one or several hydrogenases. Interestingly, also most archaeal MAGs contained genes encoding several hydrogenases indicating their important role in $\mathrm{H}_{2}$ metabolism in Bothnian Sea sediments.

\section{$\mathrm{CO}_{2}$ fixation and acetogenesis}

692 Next to the organic matter input which is eventually turned over into $\mathrm{CO}_{2}$, energy and new 693 biomass by heterotrophic organisms, $\mathrm{CO}_{2}$ fixation by autotrophs represents another organic 694 carbon input route into the sediment ecosystem. In deep anoxic sediments, autotrophs usually 695 gain energy from the oxidation of inorganic electron donors such as $\mathrm{H}_{2} \mathrm{~S}, \mathrm{PRSS}, \mathrm{H}_{2}$ and reduced 696 metals. In natural systems, $\mathrm{CO}_{2}$ can be fixed via several pathways (Berg 2011). We analyzed the 697 presence of gene biomarkers for the Wood-Ljungdahl pathway (WL) (carbon monoxide 698 dehydrogenase, Cdh/Coo), Calvin-Benson-Bassham cycle (CBB) (phosphoribulokinase (Prk) and 699 ribulose-1,5-bisphosphate carboxylase (Cbb)) and reductive citric acid cycle (rTCA) (ATP citrate 700 lyase $(\mathrm{Acl}))$

701 Here, the WL pathway is not only indicative of autotrophy, but can also be used for acetate 702 production by acetogens or assimilation of acetate, CO, or methylamines (Berg 2011). 703 Methanogenic archaea use the WL pathway for both autotrophic $\mathrm{CO}_{2}$ fixation and 704 methanogenesis (Berg 2011). The Cdh/Coo biomarker was widespread among both bacterial and 705 archaeal MAGs. As expected, the putative Syntrophobacterales SRB and other $\delta$-proteobacterial 706 MAGs contained Cdh/Coo biomarkers. Previous research showed that SRB utilize the WL 707 pathway in both reductive and oxidative directions (Schauder et al. 1988). One of the bins 708 classified as Lentisphaerales contained Cdh/Coo biomarkers. So far, no reports on the presence 
of the WL pathway in these organisms are available. Thus, they might represent novel acetate

710 producers/scavengers in methanic sediments.

711 Also putative fermenters including Spirochaetales, Anaerolineales, Aminicenantes and

712 Atribacteria contained Cdh/Coo-encoding biomarkers. In fermenters, the WL pathway was

713 discussed to function as an electron sink by reduction of $\mathrm{CO}_{2}$ to acetate (Berg 2011). Thus, those

714 organism groups might be producing acetate via this route during fermentation. The potential for

715 the WL pathway has also been detected previously in the MAG of a putatively fermentative

716 Chloroflexi bacterium RBG-2 (Hug et al. 2013) and sediment-derived genomic bins assigned to

717 Anaerolineales (Fullerton and Moyer 2016). It was discussed to be operating either under

718 heterotrophic conditions to reduce the intracellular $\mathrm{CO}_{2}$ by simultaneous oxidation of reduced

719 ferredoxin and $\mathrm{NADH}$, or under autotrophic conditions for $\mathrm{CO}_{2}$ fixation (Hug et al. 2013;

720 Ragsdale and Pierce 2008).

721 In many of the same MAGs which contained Cdh/Coo biomarkers we detected genes encoding

722 for pyruvate-ferredoxin oxidoreductase (Pfor) which might point to a link between autotrophic

$723 \mathrm{CO}_{2}$ fixation via WL pathway and TCA cycle via acetyl-CoA (Furdui and Ragsdale 2000).

$724 \mathrm{Cdh} / \mathrm{Coo}$ biomarkers were widespread among archaeal MAGs including methanogens,

725 Bathyarchaeota and Thaumarchaeota. As discussed previously, methanogens use an archaeal

726 variant of the WL pathway which is employed in hydrogenotrophic and acetotrophic

727 methanogenesis (Berg 2011; Borrel et al. 2016). Interestingly, we also detected Cdh/Coo in one

728 retrieved Methanomassiliicoccales MAG. To date, Methanomassiliicoccales methanogens, which

729 have only been described recently, were collectively implicated in lacking the WL pathway and

730 thus being restricted to $\mathrm{H}_{2}$-dependent methylotrophic methanogenesis (Borrel et al. 2016). By

731 further GenBank protein database search we found that at least two other

732 Methanomassiliicoccales genomes (RumEn M1 and RumEn M2) encode Cdh/Coo biomarkers 
733 (accession nr. KQM11260 and KQM09953). Thus, some Methanomassiliicoccales genomes

734 encode parts of the WL pathway. The detection of Cdh/Coo and other enzymes of the archaeal735 type methylotrophic branch of WL pathway in one of the Bathyarchaeota MAGs obtained in this 736 study further corroborated previous findings for this group of archaea (He et al. 2016; Lazar et al. 737 2016). Bathyarchaeota have been discussed to employ WL pathway for acetogenesis (He et al. 738 2016; Lazar et al. 2016). Similarly, Cdh/Coo and other genes encoding for the archaeal variant of

739 the WL pathway were present in Thorarchaeota MAGs which hints to their involvement in 740 acetogenesis in the analyzed sediment system.

741 Next to the WL pathway which is mainly found in anaerobic organisms operating close to the 742 thermodynamic limit, CBB cycle is employed by a variety of chemolithoautotrophic organisms 743 and can operate under higher redox potentials (Berg 2011). We analyzed the presence of two 744 biomarkers which are unique to the CBB cycle: Prk and Cbb. Among bacterial MAGs, Cbb in 745 combination with Prk was only detected in Xanthomonadales/Chromatiales and 746 Nitrosomonadales. The ability for autotrophic $\mathrm{CO}_{2}$ fixation via the $\mathrm{CBB}$ cycle has been recently 747 reported to be widespread among $\gamma$-proteobacterial lineages Woeseiaceae/JTB255 which belong 748 to the core community in diverse marine sediments (Mußmann et al. 2017) and to which 749 Bothnian Sea Xanthomonadales/Chromatiales were closely related. Several genomes have been 750 shown to encode biomarkers of CBB cycle, truncated denitrification pathway to $\mathrm{N}_{2} \mathrm{O}$ and PRSS 751 oxidation to $\mathrm{SO}_{4}{ }^{2-}$ (Dyksma et al. 2016; Mußmann et al. 2017). Xanthomonadales/Chromatiales 752 MAGs obtained from the Bothnian Sea sediment contained biomarkers for PRSS 753 transformations, denitrification and CBB cycle. Thus, these ubiquitous $\gamma$-Proteobacteria could be 754 involved in chemolithoautotrophic PRSS oxidation coupled to denitrification to $\mathrm{N}_{2} \mathrm{O}$ in the 755 coastal methanic sediments of the Bothnian Sea. The detection of CBB biomarkers in the 756 obtained Nitrosomonadales MAG was in accordance with characterized chemolithoautotrophic 
metabolism of this organism group (Utåker et al. 2002). However, as Nitrosomonadales might be

758 involved in an alternative anaerobic metabolism in the analyzed sediment, the functionality of

759 their CBB pathway remains unknown. This could be elucidated by future transcriptomic studies

760 on this ecosystem.

761 Among archaea, Cbb encoding genes were detected in methanogens. Various methanogens have

762 been shown previously to possess Cbb biomarkers, however their functionality remained debated.

763 Recently, a functional pathway involving Cbb and Prk, similar to CBB cycle in autotrophic

764 organisms, was proposed for methanogens (Kono et al. 2017). However, the ability for

765 autotrophy based on this pathway among methanogens remains unclear (Kono et al. 2017).

766 rTCA cycle biomarker Acl was detected in one of the Nitrospirales MAGs which was closely

767 related to a Nitrospira bacterium. $\mathrm{NO}_{2}{ }^{-}$-oxidizing Nitrospira have been reported previously to

768 employ rTCA cycle for $\mathrm{CO}_{2}$ fixation (Lücker et al. 2010). Thus, this autotrophic pathway seems

769 to be restricted to only one dominant group of bacteria residing in the analyzed sediment.

771 Methanogenesis-/trophy

772 Three of the obtained archaeal MAGs could be classified as methanogens: Methanosaeta, 773 Methanosarcina and Methanomassiliicoccales. Methyl-coenzyme M reductase (Mcr) was either

774 partially or fully encoded in all three genomes. Members from those three groups have been 775 described previously and represent different functional groups within methanogens.

776 Methanosaeta from the family Methanosaetaceae is an obligate acetotroph which was reported to

777 possess a high affinity to acetate and thrive under low ambient acetate concentrations (Jetten et

778 al. 1992). In contrast, Methanosarcina methanogens possess a wide substrate spectrum but low 779 affinity to acetate (Jetten et al. 1992). Despite high incompleteness of the obtained 780 Methanosarcina genome, we identified genes encoding several complexes involved in 
781 methylotrophic metabolism. Both, Methanosarcina and Methanosaeta are abundant core

782 community members in anaerobic methanic sediments (Carr et al. 2017; Webster et al. 2015). In

783 contrast, the distribution of Methanomassiliicoccales methanogens in natural methanic sediments

784 is underexplored. Originally, all described Methanomassiliicoccales were isolated or enriched

785 from intestinal tracts of animals (Dridi et al. 2012). Since then, biomarkers of

786 Methanomassiliicoccales have been detected in various sediment ecosystems and their

787 distribution was investigated in more detail recently (Becker et al. 2016; Speth and Orphan

788 2018). All physiological and genomic information available so far point to a strictly $\mathrm{H}_{2}$ -

789 dependent methylotrophic methanogenesis by a complete lack of the archaeal type WL pathway

790 (Borrel et al. 2016). The genome we obtained from the methanic sediment in this study contains

791 Cdh/Coo biomarkers which encode one of the key genes in WL pathway. Thus, its role in

792 metabolism remains unknown or it might represent a remnant of the WL pathway which has been

793 lost during Methanomassiliicoccales evolution. Interestingly, one archaeal genome (metabat2.27)

794 obtained from the Bothnian Sea sediment was closely related to available

795 Methanomassiliicoccales genomes obtained from GenBank but lacked Mcr and other essential

796 methanogenic biomarkers. It is unclear whether this organism is a methanogen and further

797 analysis of this potentially novel organism group is needed.

798 16S rRNA gene amplicon sequencing data revealed that methanotrophic ANME-2 archaea were

799 among the most abundant groups of archaea in the analyzed depth intervals. However, only one

800 highly incomplete (22.6\%) MAG classified as ANME-2a could be retrieved from the analyzed

801 sediment. The MAG did not contain Mcr biomarkers so we analyzed the metagenome for its total 802 mcrA inventory by blastx analysis (Figure 8). The result revealed ANME-like and 803 Methanosarcina-like mcrA gene reads to make up the majority of the total mcrA pool. 
804 Our results show that methanogenesis in the coastal Bothnian Sea sediments would be mostly

805 based on methylated compounds, acetate and less on $\mathrm{CO}_{2} / \mathrm{H}_{2}$. Methylated compounds are 806 common substrates in marine and brackish sediments as they are degradation products of 807 osmoregulators such as trimethylamine oxide and quaternary amines (Sørensen and Glob 1987).

808 These compounds are the so-called non-competitive substrates for methanogens, as $\mathrm{SO}_{4}{ }^{2-}$ 809 reducers do not use them for $\mathrm{SO}_{4}{ }^{2-}$ reduction (King 1984). In contrast, acetate and $\mathrm{H}_{2}$ are 810 common electron donors for both $\mathrm{SO}_{4}{ }^{2-}$ reducers and methanogens so that methanogens are often 811 outcompeted due to unfavorable substrate affinities (Oremland and Polcin 1982).

812 The potentially methanotrophic ANME-2a archaea could undergo interactions with electron813 scavenging bacteria which would respire PRSS or Fe oxides, since many bacteria possess sulfur814 based metabolisms. Or they would alternatively reduce $\mathrm{SO}_{4}{ }^{2-}$ themselves as indicated by the 815 presence of a desulfoviridin-type sulfite reductase.

\section{Conclusions}

819 The obtained genomes and total functional gene analysis of dominant organisms from the coastal 820 methanic sediments in the Bothnian Sea indicated wide genetic potential for respiratory S cycle

821 via PRSS transformations and diverse fermentation metabolisms with acetate, alcohols and $\mathrm{H}_{2}$ 822 being potentially the major metabolites in the system. The potential for the respiratory $\mathrm{N}$ cycle 823 was dominated by denitrification over DNRA and methanogenesis would be mostly based on 824 methylated compounds and acetate. The archaeal population was dominated by putative 825 anaerobic methanotrophs from the ANME-2a clade. Other abundant archaea which dominated 826 the Bothnian Sea sediments included Bathyarchaeota, Thorarchaeota and Lokiarchaeota. Their 
827 genetic potential indicated fermentations and PRSS respiration as possible lifestyle strategies. All

828 these processes will mainly depend on the quality and input amount of complex organic matter

829 which will form the basis for the food chain in anaerobic sediments. This hypothesis is feasible

830 since we observed significant differences in both archaeal and bacterial populations with distance

831 from the shoreline in the Bothnian Sea despite the similar overall concentrations of major

832 electron acceptors (e.g. Fe, $\mathrm{SO}_{4}{ }^{2-}$ ). With the PRSS, Fe oxides are thought to play a critical role in

833 the observed redox transformations (Figure 9). For future studies enrichments and physiological

834 characterizations of dominant communities would improve our understanding of their

835 physiology, in situ biological function and biogeochemical impact. 


\section{References}

Abeliovich, A., and A. Vonshak. 1992. Anaerobic metabolism of Nitrosomonas europaea. Archives of Microbiology 158: 267-270.

Algesten, G. and others 2006. Organic carbon budget for the Gulf of Bothnia. Journal of Marine Systems 63: $155-161$.

Alneberg, J. and others 2014. Binning metagenomic contigs by coverage and composition. Nature methods 11: 1144-1146.

Aromokeye, D. A. and others 2018. Temperature Controls Crystalline Iron Oxide Utilization by Microbial Communities in Methanic Ferruginous Marine Sediment Incubations. Frontiers in Microbiology 9.

Asmala, E., J. Carstensen, D. J. Conley, C. P. Slomp, J. Stadmark, and M. Voss. 2017. Efficiency of the coastal filter: Nitrogen and phosphorus removal in the Baltic Sea. Limnology and Oceanography 62: S222-S238.

Baker, B. J., C. S. Lazar, A. P. Teske, and G. J. Dick. 2015. Genomic resolution of linkages in carbon, nitrogen, and sulfur cycling among widespread estuary sediment bacteria. Microbiome 3: 14 .

Bange, H. W., U. H. Bartell, S. Rapsomanikis, and M. O. Andreae. 1994. Methane in the Baltic and North Seas and a reassessment of the marine emissions of methane. Global Biogeochemical Cycles 8: 465-480.

Becker, K. W., F. J. Elling, M. Y. Yoshinaga, A. Söllinger, T. Urich, and K.-U. Hinrichs. 2016. Unusual Butane- and Pentanetriol-Based Tetraether Lipids in Methanomassiliicoccus luminyensis, a Representative of the Seventh Order of Methanogens. Applied and Environmental Microbiology 82: 4505-4516.

Berg, I. A. 2011. Ecological Aspects of the Distribution of Different Autotrophic $\mathrm{CO}_{2}$ Fixation Pathways. Applied and Environmental Microbiology 77: 1925-1936.

Bolhuis, H., H. Schluepmann, J. Kristalijn, Z. Sulaiman, and D. J. Marshall. 2014. Molecular analysis of bacterial diversity in mudflats along the salinity gradient of an acidified tropical Bornean estuary (South East Asia). Aquatic Biosystems 10: 10.

Bonaglia, S. and others 2017. The fate of fixed nitrogen in marine sediments with low organic loading: an in situ study. Biogeosciences 14: 285-300.

Borrel, G., P. S. Adam, and S. Gribaldo. 2016. Methanogenesis and the Wood-Ljungdahl Pathway: An Ancient, Versatile, and Fragile Association. Genome Biology and Evolution 8: 1706-1711.

Breznak, J. A., and F. Warnecke. 2008. Spirochaeta cellobiosiphila sp. nov., a facultatively anaerobic, marine spirochaete. International Journal of Systematic and Evolutionary Microbiology 58: 27622768.

Brunner, B., G. L. Arnold, H. Røy, I. A. Müller, and B. B. Jørgensen. 2016. Off Limits: Sulfate below the Sulfate-Methane Transition. Frontiers in Earth Science 4.

Bushnell, B. BBMap. sourceforge.net/projects/bbmap/ (unpublished).

Caporaso, J. G. and others 2012. Ultra-high-throughput microbial community analysis on the Illumina HiSeq and MiSeq platforms. The ISME Journal 6: 1621.

Cardman, Z. and others 2014. Verrucomicrobia Are Candidates for Polysaccharide-Degrading Bacterioplankton in an Arctic Fjord of Svalbard. Applied and Environmental Microbiology 80: 3749-3756. 
Carr, S. A., B. N. Orcutt, K. W. Mandernack, and J. R. Spear. 2015. Abundant Atribacteria in deep marine sediment from the Adélie Basin, Antarctica. Frontiers in Microbiology 6: 872.

Carr, S. A. and others 2017. Acetoclastic Methanosaeta are dominant methanogens in organic-rich Antarctic marine sediments. The ISME Journal 12: 330.

Castelle, Cindy J. and others 2015. Genomic Expansion of Domain Archaea Highlights Roles for Organisms from New Phyla in Anaerobic Carbon Cycling. Current Biology 25: 690-701.

Dridi, B., M.-L. Fardeau, B. Ollivier, D. Raoult, and M. Drancourt. 2012. Methanomassiliicoccus luminyensis gen. nov., sp. nov., a methanogenic archaeon isolated from human faeces. International Journal of Systematic and Evolutionary Microbiology 62: 1902-1907.

Dyksma, S. and others 2016. Ubiquitous Gammaproteobacteria dominate dark carbon fixation in coastal sediments. The ISME Journal 10: 1939-1953.

Edgar, R. C., B. J. Haas, J. C. Clemente, C. Quince, and R. Knight. 2011. UCHIME improves sensitivity and speed of chimera detection. Bioinformatics 27: 2194-2200.

Egger, M., T. Jilbert, T. Behrends, C. Rivard, and C. P. Slomp. 2015a. Vivianite is a major sink for phosphorus in methanogenic coastal surface sediments. Geochimica et Cosmochimica Acta 169: 217-235.

Egger, M. and others 2015b. Iron-Mediated Anaerobic Oxidation of Methane in Brackish Coastal Sediments. Environmental Science \& Technology 49: 277-283.

Evans, P. N. and others 2015. Methane metabolism in the archaeal phylum Bathyarchaeota revealed by genome-centric metagenomics. Science 350: 434-438.

Finke, N., V. Vandieken, and B. B. Jørgensen. 2007. Acetate, lactate, propionate, and isobutyrate as electron donors for iron and sulfate reduction in Arctic marine sediments, Svalbard. FEMS Microbiology Ecology 59: 10-22.

Fricke, W. F. and others 2006. The Genome Sequence of Methanosphaera stadtmanae Reveals Why This Human Intestinal Archaeon Is Restricted to Methanol and $\mathrm{H}_{2}$ for Methane Formation and ATP Synthesis. Journal of Bacteriology 188: 642-658.

Fullerton, H., and C. L. Moyer. 2016. Comparative Single-Cell Genomics of Chloroflexi from the Okinawa Trough Deep-Subsurface Biosphere. Applied and Environmental Microbiology 82: 3000-3008.

Furdui, C., and S. W. Ragsdale. 2000. The Role of Pyruvate Ferredoxin Oxidoreductase in Pyruvate Synthesis during Autotrophic Growth by the Wood-Ljungdahl Pathway. Journal of Biological Chemistry 275: 28494-28499.

Ghosh, W., and B. Dam. 2009. Biochemistry and molecular biology of lithotrophic sulfur oxidation by taxonomically and ecologically diverse bacteria and archaea. FEMS Microbiology Reviews 33: 999-1043.

Green-Saxena, A., A. E. Dekas, N. F. Dalleska, and V. J. Orphan. 2014. Nitrate-based niche differentiation by distinct sulfate-reducing bacteria involved in the anaerobic oxidation of methane. The ISME Journal 8: 150-163.

Hallberg, K. B., S. Hedrich, and D. B. Johnson. 2011. Acidiferrobacter thiooxydans, gen. nov. sp. nov.; an acidophilic, thermo-tolerant, facultatively anaerobic iron- and sulfur-oxidizer of the family Ectothiorhodospiraceae. Extremophiles 15: 271-279. 
Harris, R. L. and others 2018. Draft Genome Sequence of "Candidatus Bathyarchaeota” Archaeon BE326-BA-RLH, an Uncultured Denitrifier and Putative Anaerobic Methanotroph from South Africa’s Deep Continental Biosphere. Microbiology Resource Announcements 7: e01295-01218.

Harrison, B. K., A. Myrbo, B. E. Flood, and J. V. Bailey. 2016. Identification of subannual patterns in microbial community signatures from individual sedimentary laminae using a freeze-coring approach. Limnology and Oceanography 61: 735-747.

Harrison, B. K., H. Zhang, W. Berelson, and V. J. Orphan. 2009. Variations in Archaeal and Bacterial Diversity Associated with the Sulfate-Methane Transition Zone in Continental Margin Sediments (Santa Barbara Basin, California). Applied and Environmental Microbiology 75: 1487-1499.

He, Y. and others 2016. Genomic and enzymatic evidence for acetogenesis among multiple lineages of the archaeal phylum Bathyarchaeota widespread in marine sediments. Nature Microbiology 1: 16035.

Hellemann, D., P. Tallberg, I. Bartl, M. Voss, and S. Hietanen. 2017. Denitrification in an oligotrophic estuary: a delayed sink for riverine nitrate. Marine Ecology Progress Series 583: 63-80.

Herlemann, D. P. R., M. Labrenz, K. Jürgens, S. Bertilsson, J. J. Waniek, and A. F. Andersson. 2011. Transitions in bacterial communities along the $2000 \mathrm{~km}$ salinity gradient of the Baltic Sea. The ISME Journal 5: 1571.

Holmkvist, L., T. G. Ferdelman, and B. B. Jørgensen. 2011. A cryptic sulfur cycle driven by iron in the methane zone of marine sediment (Aarhus Bay, Denmark). Geochimica et Cosmochimica Acta 75: 3581-3599.

Hug, L. A. and others 2013. Community genomic analyses constrain the distribution of metabolic traits across the Chloroflexi phylum and indicate roles in sediment carbon cycling. Microbiome 1: 22.

Hugoni, M. and others 2015. Temporal dynamics of active Archaea in oxygen-depleted zones of two deep lakes. Environmental Microbiology Reports 7: 321-329.

Hulth, S., R. C. Aller, and F. Gilbert. 1999. Coupled anoxic nitrification/manganese reduction in marine sediments. Geochimica et Cosmochimica Acta 63: 49-66.

Huson, D. H., A. F. Auch, J. Qi, and S. C. Schuster. 2007. MEGAN analysis of metagenomic data. Genome Research 17: 377-386.

Imachi, H., and S. Sakai. 2015. Methanoregulaceae. Bergey's Manual of Systematics of Archaea and Bacteria. John Wiley \& Sons, Ltd.

Jagersma, G. C. and others 2009. Microbial diversity and community structure of a highly active anaerobic methane-oxidizing sulfate-reducing enrichment. Environmental Microbiology 11: 3223-3232.

Jetten, M. S. M., A. J. M. Stams, and A. J. B. Zehnder. 1992. Methanogenesis from acetate: a comparison of the acetate metabolism in Methanothrix soehngenii and Methanosarcina spp. FEMS Microbiology Letters 88: 181-198.

Kang, D. D., J. Froula, R. Egan, and Z. Wang. 2015. MetaBAT, an efficient tool for accurately reconstructing single genomes from complex microbial communities. PeerJ 3: e1165.

King, G. M. 1984. Utilization of hydrogen, acetate, and "noncompetitive"; substrates by methanogenic bacteria in marine sediments. Geomicrobiology Journal 3: 275-306.

Knittel, K., and A. Boetius. 2009. Anaerobic Oxidation of Methane: Progress with an Unknown Process. Annual Review of Microbiology 63: 311-334.

Kono, T. and others 2017. A RuBisCO-mediated carbon metabolic pathway in methanogenic archaea. Nature Communications 8: 14007. 
Kozich, J. J., S. L. Westcott, N. T. Baxter, S. K. Highlander, and P. D. Schloss. 2013. Development of a dual-index sequencing strategy and curation pipeline for analyzing amplicon sequence data on the MiSeq Illumina sequencing platform. Applied and Environmental Microbiology 79: 5112-5120.

Krekeler, D., and H. Cypionka. 1995. The preferred electron acceptor of Desulfovibrio desulfuricans CSN. FEMS Microbiology Ecology 17: 271-277.

Lazar, C. S. and others 2016. Genomic evidence for distinct carbon substrate preferences and ecological niches of Bathyarchaeota in estuarine sediments. Environmental Microbiology 18: 1200-1211.

Leloup, J., A. Loy, N. J. Knab, C. Borowski, M. Wagner, and B. B. Jørgensen. 2007. Diversity and abundance of sulfate-reducing microorganisms in the sulfate and methane zones of a marine sediment, Black Sea. Environmental Microbiology 9: 131-142.

Lenstra, W. K., M. Egger, N. A. G. M. van Helmond, E. Kritzberg, D. J. Conley, and C. P. Slomp. 2018. Variations in river input of iron impact sedimentary phosphorus burial in an oligotrophic Baltic Sea estuary. Biogeosciences 15: 6979-6996.

Li, D., C.-M. Liu, R. Luo, K. Sadakane, and T.-W. Lam. 2015. MEGAHIT: an ultra-fast single-node solution for large and complex metagenomics assembly via succinct de Bruijn graph. Bioinformatics 31: 1674-1676.

Li, D. and others 2016. MEGAHIT v1.0: A fast and scalable metagenome assembler driven by advanced methodologies and community practices. Methods 102: 3-11.

Li, H., and R. Durbin. 2010. Fast and accurate long-read alignment with Burrows-Wheeler transform. Bioinformatics 26: 589-595.

Li, H. and others 2009. The Sequence Alignment/Map format and SAMtools. Bioinformatics 25: 20782079.

Linz, A. M. and others 2017. Bacterial Community Composition and Dynamics Spanning Five Years in Freshwater Bog Lakes. mSphere 2: e00169-00117.

Liu, Y., and W. B. Whitman. 2008. Metabolic, Phylogenetic, and Ecological Diversity of the Methanogenic Archaea. Annals of the New York Academy of Sciences 1125: 171-189.

Lloyd, K. G. and others 2013. Predominant archaea in marine sediments degrade detrital proteins. Nature 496: 215.

López, N. I., and C. M. Duarte. 2004. Dimethyl sulfoxide (DMSO) reduction potential in Mediterranean seagrass (Posidonia oceanica) sediments. Journal of Sea Research 51: 11-20.

Lu, Y. Y., T. Chen, J. A. Fuhrman, and F. Sun. 2017. COCACOLA: binning metagenomic contigs using sequence COmposition, read CoverAge, CO-alignment and paired-end read LinkAge. Bioinformatics 33: 791-798.

Lücker, S. and others 2010. A Nitrospira metagenome illuminates the physiology and evolution of globally important nitrite-oxidizing bacteria. Proceedings of the National Academy of Sciences 107: $13479-13484$.

Ludwig, W. and others 2004. ARB: a software environment for sequence data. Nucleic Acids Research 32: 1363-1371.

Lüke, C., D. R. Speth, M. A. R. Kox, L. Villanueva, and M. S. M. Jetten. 2016. Metagenomic analysis of nitrogen and methane cycling in the Arabian Sea oxygen minimum zone. PeerJ 4: e1924.

Luther, G. W., B. Sundby, B. L. Lewis, P. J. Brendel, and N. Silverberg. 1997. Interactions of manganese with the nitrogen cycle: Alternative pathways to dinitrogen. Geochimica et Cosmochimica Acta 61: 4043-4052. 
Martinez-Garcia, M. and others 2012. Capturing Single Cell Genomes of Active Polysaccharide Degraders: An Unexpected Contribution of Verrucomicrobia. PLoS One 7: e35314.

McGlynn, S. E., G. L. Chadwick, C. P. Kempes, and V. J. Orphan. 2015. Single cell activity reveals direct electron transfer in methanotrophic consortia. Nature 526: 531.

Milucka, J. and others 2012. Zero-valent sulphur is a key intermediate in marine methane oxidation. Nature 491: 541.

Miyazaki, M., S. Sakai, Y. Yamanaka, Y. Saito, K. Takai, and H. Imachi. 2014. Spirochaeta psychrophila sp. nov., a psychrophilic spirochaete isolated from subseafloor sediment, and emended description of the genus Spirochaeta. International Journal of Systematic and Evolutionary Microbiology 64: 2798-2804.

Mogollón, J. M., K. Mewes, and S. Kasten. 2016. Quantifying manganese and nitrogen cycle coupling in manganese-rich, organic carbon-starved marine sediments: Examples from the Clarion-Clipperton fracture zone. Geophysical Research Letters 43: 7114-7123.

Moriya, Y., M. Itoh, S. Okuda, A. C. Yoshizawa, and M. Kanehisa. 2007. KAAS: an automatic genome annotation and pathway reconstruction server. Nucleic Acids Research 35: W182-W185.

Mußmann, M., P. Pjevac, K. Krüger, and S. Dyksma. 2017. Genomic repertoire of the Woeseiaceae/JTB255, cosmopolitan and abundant core members of microbial communities in marine sediments. The ISME Journal 11: 1276.

Na, H., M. A. Lever, K. U. Kjeldsen, F. Schulz, and B. B. Jørgensen. 2015. Uncultured Desulfobacteraceae and Crenarchaeotal group C3 incorporate 13C-acetate in coastal marine sediment. Environmental Microbiology Reports 7: 614-622.

Na, S.-I., Y. O. Kim, S.-H. Yoon, S.-m. Ha, I. Baek, and J. Chun. 2018. UBCG: Up-to-date bacterial core gene set and pipeline for phylogenomic tree reconstruction. Journal of Microbiology 56: 280-285.

Newberry, C. J., G. Webster, B. A. Cragg, R. J. Parkes, A. J. Weightman, and J. C. Fry. 2004. Diversity of prokaryotes and methanogenesis in deep subsurface sediments from the Nankai Trough, Ocean Drilling Program Leg 190. Environmental Microbiology 6: 274-287.

Nobu, M. K. and others 2016. Phylogeny and physiology of candidate phylum 'Atribacteria' (OP9/JS1) inferred from cultivation-independent genomics. The ISME Journal 10: 273-286.

Oksanen, J. and others 2018. Vegan: Community Ecology Package. R package version 2.3-3.

Oni, O. and others 2015a. Distinct microbial populations are tightly linked to the profile of dissolved iron in the methanic sediments of the Helgoland mud area, North Sea. Frontiers in Microbiology 6: 365.

Oni, O. E. and others 2015b. Microbial Communities and Organic Matter Composition in Surface and Subsurface Sediments of the Helgoland Mud Area, North Sea. Frontiers in Microbiology 6: 1290.

Oremland, R. S., and S. Polcin. 1982. Methanogenesis and Sulfate Reduction: Competitive and Noncompetitive Substrates in Estuarine Sediments. Applied and Environmental Microbiology 44: 1270-1276.

Oren, A. 2014. The Family Methanobacteriaceae, p. 165-193. In E. Rosenberg, E. F. DeLong, S. Lory, E. Stackebrandt and F. Thompson [eds.], The Prokaryotes: Other Major Lineages of Bacteria and The Archaea. Springer Berlin Heidelberg.

Parks, D. H., M. Imelfort, C. T. Skennerton, P. Hugenholtz, and G. W. Tyson. 2015. CheckM: assessing the quality of microbial genomes recovered from isolates, single cells, and metagenomes. Genome research 25: 1043-1055. 
1064

1065

1066

1067

1068

1069

1070

1071

1072

1073

1074

1075

1076

1077

1078

1079

1080

1081

1082

1083

1084

1085 1086

1087

1088

1089

Pester, M., C. Schleper, and M. Wagner. 2011. The Thaumarchaeota: an emerging view of their phylogeny and ecophysiology. Current Opinion in Microbiology 14: 300-306.

Pfennig, N., F. Widdel, and H. G. Trüper. 1981. The Dissimilatory Sulfate-Reducing Bacteria, p. 926-940. In M. P. Starr, H. Stolp, H. G. Trüper, A. Balows and H. G. Schlegel [eds.], The Prokaryotes: A Handbook on Habitats, Isolation, and Identification of Bacteria. Springer Berlin Heidelberg.

Plugge, C. M., W. Zhang, J. C. M. Scholten, and A. J. M. Stams. 2011. Metabolic Flexibility of SulfateReducing Bacteria. Frontiers in Microbiology 2: 81.

Pruesse, E. and others 2007. SILVA: a comprehensive online resource for quality checked and aligned ribosomal RNA sequence data compatible with ARB. Nucleic Acids Research 35.

Ragsdale, S. W., and E. Pierce. 2008. Acetogenesis and the Wood-Ljungdahl Pathway of CO(2) Fixation. Biochimica et Biophysica Acta 1784: 1873-1898.

Rasigraf, O., J. Schmitt, M. S. M. Jetten, and C. Lüke. 2017. Metagenomic potential for and diversity of $\mathrm{N}$-cycle driving microorganisms in the Bothnian Sea sediment. MicrobiologyOpen 6: e00475-n/a.

Reyes, C. and others 2016. Bacterial communities potentially involved in iron-cycling in Baltic Sea and North Sea sediments revealed by pyrosequencing. FEMS Microbiology Ecology 92: fiw054fiw054.

Reyes, C., D. Schneider, M. Lipka, A. Thürmer, M. E. Böttcher, and M. W. Friedrich. 2017. Nitrogen Metabolism Genes from Temperate Marine Sediments. Marine Biotechnology 19: 175-190.

Roalkvam, I., H. Dahle, Y. Chen, S. Jørgensen, H. Haflidason, and I. Steen. 2012. Fine-Scale Community Structure Analysis of ANME in Nyegga Sediments with High and Low Methane Flux. Frontiers in Microbiology 3.

Roalkvam, I. and others 2011. New insight into stratification of anaerobic methanotrophs in cold seep sediments. FEMS Microbiology Ecology 78: 233-243.

Rooze, J., M. Egger, I. Tsandev, and C. P. Slomp. 2016. Iron-dependent anaerobic oxidation of methane in coastal surface sediments: Potential controls and impact. Limnology and Oceanography 61: S267S282.

RStudio Team. 2015. RStudio: Integrated Development for R. RStudio, Inc., Boston, MA URL http://www.rstudio.com/.

Ruff, S. E., J. F. Biddle, A. P. Teske, K. Knittel, A. Boetius, and A. Ramette. 2015. Global dispersion and local diversification of the methane seep microbiome. Proceedings of the National Academy of Sciences 112: 4015-4020.

Schauder, R., A. Preuß, M. Jetten, and G. Fuchs. 1988. Oxidative and reductive acetyl CoA/carbon monoxide dehydrogenase pathway in Desulfobacterium autotrophicum. Archives of Microbiology 151: 84-89.

Scheller, S., H. Yu, G. L. Chadwick, S. E. McGlynn, and V. J. Orphan. 2016. Artificial electron acceptors decouple archaeal methane oxidation from sulfate reduction. Science 351: 703-707.

Schlitzer, R. 2015. Ocean Data View. http://odv.awi.de.

Schmidt, I. and others 2002. Aerobic and anaerobic ammonia oxidizing bacteria - competitors or natural partners? FEMS Microbiology Ecology 39: 175-181.

Schreiber, L., T. Holler, K. Knittel, A. Meyerdierks, and R. Amann. 2010. Identification of the dominant sulfate-reducing bacterial partner of anaerobic methanotrophs of the ANME-2 clade. Environmental Microbiology 12: 2327-2340. 
Seitz, K. W., C. S. Lazar, K.-U. Hinrichs, A. P. Teske, and B. J. Baker. 2016. Genomic reconstruction of a novel, deeply branched sediment archaeal phylum with pathways for acetogenesis and sulfur reduction. The ISME Journal 10: 1696-1705.

Shaw, D. G., and D. J. McIntosh. 1990. Acetate in recent anoxic sediments: Direct and indirect measurements of concentration and turnover rates. Estuarine, Coastal and Shelf Science 31: 775788.

Shivani, Y., Y. Subhash, L. Tushar, C. Sasikala, and C. V. Ramana. 2015. Spirochaeta lutea sp. nov., isolated from marine habitats and emended description of the genus Spirochaeta. Systematic and Applied Microbiology 38: 110-114.

Sieber, C. M. K. and others 2018. Recovery of genomes from metagenomes via a dereplication, aggregation and scoring strategy. Nature Microbiology 3: 836-843.

Slomp, C. P., H. P. Mort, T. Jilbert, D. C. Reed, B. G. Gustafsson, and M. Wolthers. 2013. Coupled Dynamics of Iron and Phosphorus in Sediments of an Oligotrophic Coastal Basin and the Impact of Anaerobic Oxidation of Methane. PLOS ONE 8: e62386.

Sørensen, J., and E. Glob. 1987. Influence of benthic fauna on trimethylamine concentrations in coastal marine sediments. Marine Ecology Progress Series: 15-21.

Speth, D. R., and V. J. Orphan. 2018. Metabolic marker gene mining provides insight in global mcrA diversity and, coupled with targeted genome reconstruction, sheds further light on metabolic potential of the Methanomassiliicoccales. PeerJ 6: e5614.

Storesund, J. E., and L. Øvreås. 2013. Diversity of Planctomycetes in iron-hydroxide deposits from the Arctic Mid Ocean Ridge (AMOR) and description of Bythopirellula goksoyri gen. nov., sp. nov., a novel Planctomycete from deep sea iron-hydroxide deposits. Antonie van Leeuwenhoek 104: 569-584.

Takai, K., and K. Horikoshi. 2000. Rapid detection and quantification of members of the archaeal community by quantitative PCR using fluorogenic probes. Applied and environmental microbiology 66: 5066-5072.

Thamdrup, B., and T. Dalsgaard. 2000. The fate of ammonium in anoxic manganese oxide-rich marine sediment. Geochimica et Cosmochimica Acta 64: 4157-4164.

Thorup, C., A. Schramm, A. J. Findlay, K. W. Finster, and L. Schreiber. 2017. Disguised as a Sulfate Reducer: Growth of the Deltaproteobacterium Desulfurivibrio alkaliphilus by Sulfide Oxidation with Nitrate. mBio 8.

Treude, T., M. Krüger, A. Boetius, and B. B. Jørgensen. 2005. Environmental control on anaerobic oxidation of methane in the gassy sediments of Eckernförde Bay (German Baltic). Limnology and Oceanography 50: 1771-1786.

Utåker, J. B., K. Andersen, Å. Aakra, B. Moen, and I. F. Nes. 2002. Phylogeny and Functional Expression of Ribulose 1,5-Bisphosphate Carboxylase/Oxygenase from the Autotrophic Ammonia-Oxidizing Bacterium Nitrosospira sp.Isolate 40KI. Journal of Bacteriology 184: 468-478.

Vallenet, D. and others 2006. MaGe: a microbial genome annotation system supported by synteny results. Nucleic Acids Research 34: 53-65.

Weber, E. B., L. E. Lehtovirta-Morley, J. I. Prosser, and C. Gubry-Rangin. 2015. Ammonia oxidation is not required for growth of Group 1.1c soil Thaumarchaeota. FEMS Microbiology Ecology 91: fiv001-fiv001.

Weber, S., S. Stubner, and R. Conrad. 2001. Bacterial Populations Colonizing and Degrading Rice Straw in Anoxic Paddy Soil. Applied and Environmental Microbiology 67: 1318-1327. 
Webster, G. and others 2015. Archaeal community diversity and abundance changes along a natural salinity gradient in estuarine sediments. FEMS Microbiology Ecology 91: 1-18.

Webster, G., J. Rinna, E. G. Roussel, J. C. Fry, A. J. Weightman, and R. J. Parkes. 2010. Prokaryotic functional diversity in different biogeochemical depth zones in tidal sediments of the Severn Estuary, UK, revealed by stable-isotope probing. FEMS Microbiology Ecology 72: 179-197.

Weier, K. L., J. W. Doran, J. F. Power, and D. T. Walters. 1993. Denitrification and the Dinitrogen/Nitrous Oxide Ratio as Affected by Soil Water, Available Carbon, and Nitrate. Soil Science Society of America Journal 57: 66-72.

Wickham, H. 2016. ggplot2: Elegant Graphics for Data Analysis. Springer-Verlag New York.

Winkelmann, N. and others 2010. Determination of the Diversity of Rhodopirellula Isolates from European Seas by Multilocus Sequence Analysis. Applied and Environmental Microbiology 76: 776-785.

Wu, Y. W., B. A. Simmons, and S. W. Singer. 2016. MaxBin 2.0: an automated binning algorithm to recover genomes from multiple metagenomic datasets. Bioinformatics 32: 605-607.

Yamada, T. and others 2006. Anaerolinea thermolimosa sp. nov., Levilinea saccharolytica gen. nov., sp. nov. and Leptolinea tardivitalis gen. nov., sp. nov., novel filamentous anaerobes, and description of the new classes Anaerolineae classis nov. and Caldilineae classis nov. in the bacterial phylum Chloroflexi. International Journal of Systematic and Evolutionary Microbiology 56: 1331-1340.

Zeng, Y.-X., Y. Yu, H.-R. Li, and W. Luo. 2017. Prokaryotic Community Composition in Arctic Kongsfjorden and Sub-Arctic Northern Bering Sea Sediments As Revealed by 454 Pyrosequencing. Frontiers in Microbiology 8.

Zopfi, J., T. G. Ferdelman, and H. Fossing. 2004. Distribution and fate of sulfur intermediates—sulfite, tetrathionate, thiosulfate, and elemental sulfur-in marine sediments. In J. P. Amend, K. J. Edwards and T. W. Lyons [eds.], Sulfur Biogeochemistry - Past and Present. Geological Society of America. 


\section{Acknowledgements}

1161 We would like to thank Theo van Alen and Geert Cremers for sequencing the metagenomes. The

1162 captain, crew and scientific participants aboard R/V Lotty are thanked for their assistance during 1163 sampling in August 2015. This work was carried out on the Dutch national e-infrastructure with 1164 the support of SURF Cooperative. LABGeM (Genoscope, Institute of Genomics, CEA Sciences) 1165 and the National infrastructure "France Génomique" are acknowledged for support within the 1166 MicroScope annotation platform. O.R., M.S.M.J. and C.P.S. were supported by NESSC (grant 1167 number 024002001), J.F. and M.S.M.J were supported by the SIAM Gravitation Grant on 1168 Anaerobic Microbiology (Netherlands Organization for Scientific Research, SIAM 024002002 )

1169 and ERC AG (nr. 339880), C.P.S., W.L. and N.A.G.M.v.H. were supported by NWO (grant 1170 number 865.13.005) and the European Union and FORMAS through BONUS COCOA (grant 1171 number 2112932-1). 


\section{Figure Legends}

1173 Figure 1: (a) Locations of sampling sites N10, NB8 and US5B in the Bothnian Sea; (b) Locations 1174 of both coastal sites N10 and NB8 in the Öre Estuary in the Bothnian Sea. Figure drawn using 1175 Ocean Data View (Schlitzer 2015).

1176 Figure 2: Geochemical profiles for sites N10, NB8 and US5B. Porewater profiles of $\mathrm{SO}_{4}{ }^{2-}$, 1177 sulfide $\left(\sum \mathrm{H}_{2} \mathrm{~S}=\mathrm{H}_{2} \mathrm{~S}+\mathrm{HS}^{-}+\mathrm{S}^{2-}\right), \mathrm{Fe}^{2+}, \mathrm{CH}_{4}$ and $\mathrm{NH}_{4}{ }^{+}$are shown. Note the different scales for 1178 site N10.

1179 Figure 3: Distribution of archaeal taxons based on 16S rRNA amplicon analysis for sediment 1180 transects from N10, NB8 and US5B sites in the Bothnian Sea.

1181 Figure 4: Distribution of bacterial taxons based on 16S rRNA amplicon analysis for sediment 1182 transects from N10, NB8 and US5B sites in the Bothnian Sea.

1183 Figure 5: Non-metric multidimensional scaling (nMDS) analysis of sedimentary community 1184 populations from sampling sites N10, NB8 and US5B of (a) bacteria and (b) archaea based on 1185 16S rRNA gene amplicon data. A dissimilarity matrix was calculated using the Bray-Curtis 1186 dissimilarity index in R. Symbols represent individual sampling depths of each sampling site, 1187 colors different sampling sites.

1188 Figure 6: Metabolic potential for respiratory sulfur (a) and nitrogen (b) cycle reactions identified 1189 in metagenomic bins obtained from the iron-rich methanic sediment at site NB8 in the Bothnian 1190 Sea. Key enzymes catalyzing each process are shown. Abbreviations: PRSS, partially reduced 1191 sulfur species (include tetrathionate, thiosulfate, sulfite, polysulfide, elemental sulfur); Sdo, sulfur 1192 dioxygenase; Sox, sulfur-oxidizing multi-enzyme complex; Apr, adenylylsulfate (APS) 1193 reductase; Dsr, dissimilatory (bi)sulfite reductase; Sqr, sulfide:quinone oxidoreductase; Ttr, 
1194 tetrathionate reductase; Asr, sulfite reductase; Hyd, sulfhydrogenase; Phs, thiosulfate reductase;

1195 Nar, nitrate reductase; Nxr, nitrate:nitrite oxidoreductase; Nap, periplasmic nitrate reductase; Nrf,

1196 nitrite reductase $\left(\mathrm{NH}_{4}{ }^{+}\right.$forming); Amo, ammonia monooxygenase; Hao, hydroxylamine

1197 oxidoreductase; Nos, nitrous oxide reductase; NirK, Cu-containing nitrite reductase (NO

1198 forming); NirS, Fe-containing nitrite reductase (NO forming); Nor, nitric oxide reductase.

1199 Figure 7: Overview for presence of functional biomarkers in genome bins obtained from the Fe1200 rich methanic sediment layer at coastal site NB8 in the Bothnian Sea. Analysis was performed for

1201 key genes encoding enzymes involved in processes of respiratory nitrogen (N) and sulfur (S)

1202 cycles, fermentation product metabolism, autotrophy/acetogenesis and methanogenesis.

1203 Abbreviations: Form., formate; But., butyrate; Eth., ethanol; Prop., propionate; WL, Wood-

1204 Ljungdahl pathway; CBB, Calvin-Benson-Bessham cycle; rTCA, reverse tricarboxylic acid

1205 cycle.

1206 Figure 8: Domain distribution (left) and estimation of community diversity (right) in the Fe-rich 1207 methanic zone of site NB8 in the Bothnian Sea. Complete 16S rRNA and mcrA gene sequences 1208 were obtained from the assembled metagenome.

1209 Figure 9: Simplified overview of predicted processes involving Fe and sulfur to take place in the 1210 analyzed coastal anaerobic sediments in the Bothnian Sea at site NB8. Ferrihydrite would 1211 represent the major electron acceptor in the analyzed sediments and be involved in the biotic and 1212 abiotic oxidation of sulfide and fermentation products. Anaerobic oxidation of methane could 1213 potentially be fueled by the reduction of PRSS formed by ferrihydrite or ferrihydrite directly. 1214 Acetate would be one of the key metabolites formed during the primary and secondary 
1215 fermentations. The reduced Fe would react with the free sulfide and form insoluble iron sulfides.

1216 Abbreviations: PRSS, partially reduced sulfur species 


\section{Tables}

1218 Table 1: Characteristics of the investigated sites N10, NB8 and US5B in the Bothnian Sea. The

1219 data for water depth, temperature, coordinates, organic carbon content and sedimentation rates

1220 were compiled with from Lenstra et al. 2018 and Egger et al. 2015a. Abbreviations: mbss, meters

1221 below sea surface.

\begin{tabular}{lllllll}
\hline Site & $\begin{array}{l}\text { Water depth } \\
\text { (mbss) }\end{array}$ & $\begin{array}{l}\text { Temperature } \\
{ }^{\circ} \mathrm{C}\end{array}$ & $\begin{array}{l}\text { Latitude } \\
{ }^{\circ} \mathrm{N}\end{array}$ & $\begin{array}{l}\text { Longitude } \\
{ }^{\circ} \mathrm{E}\end{array}$ & $\mathrm{C}_{\text {org }}$ (wt. \%) & $\begin{array}{l}\text { Sed. rate (cm } \\
\left.\text { year }^{-1}\right)\end{array}$ \\
\hline N10 & 20.8 & 7.8 & 63.293 & 19.462 & $3.40( \pm 0.70)$ & 0.25 \\
NB8 & 33.2 & 6.3 & 63.291 & 19.495 & $3.85( \pm 0.07)$ & 1 \\
US5B & 214 & 5.0 & 62.351 & 19.581 & $2.58( \pm 0.21)$ & 1.3 \\
\hline
\end{tabular}


1222 Figure 1

A

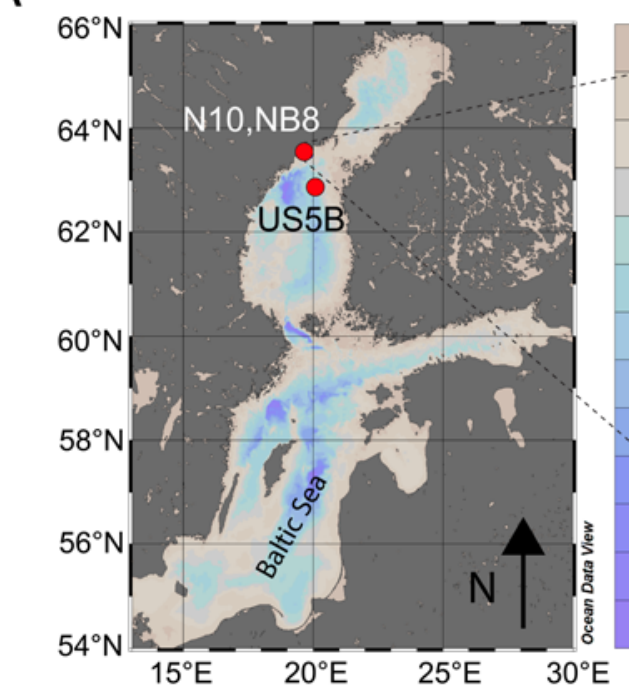

B

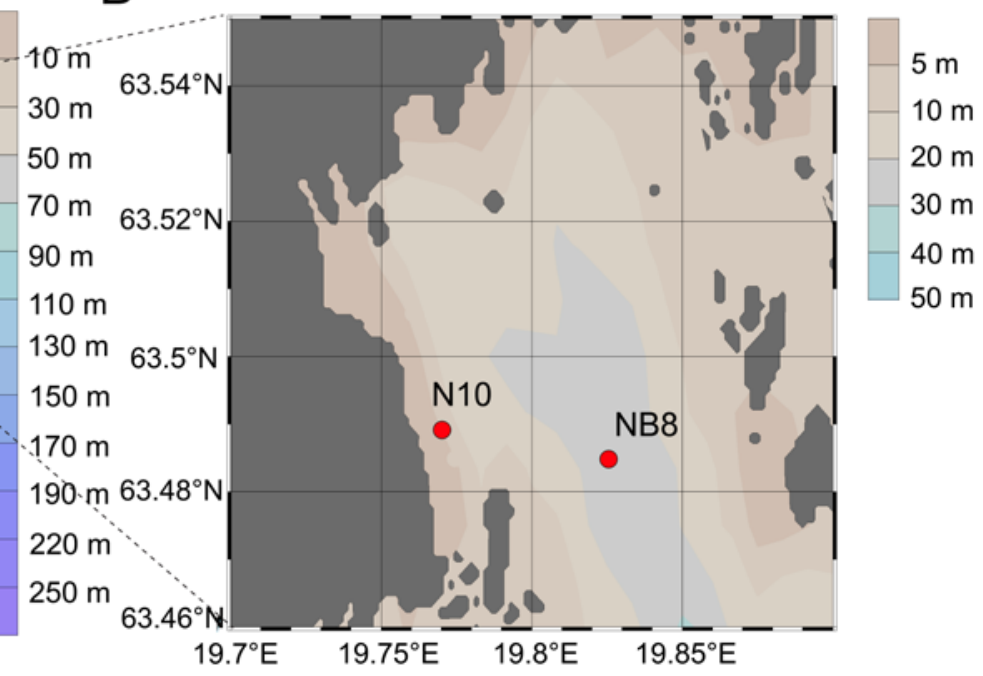


1224 Figure 2

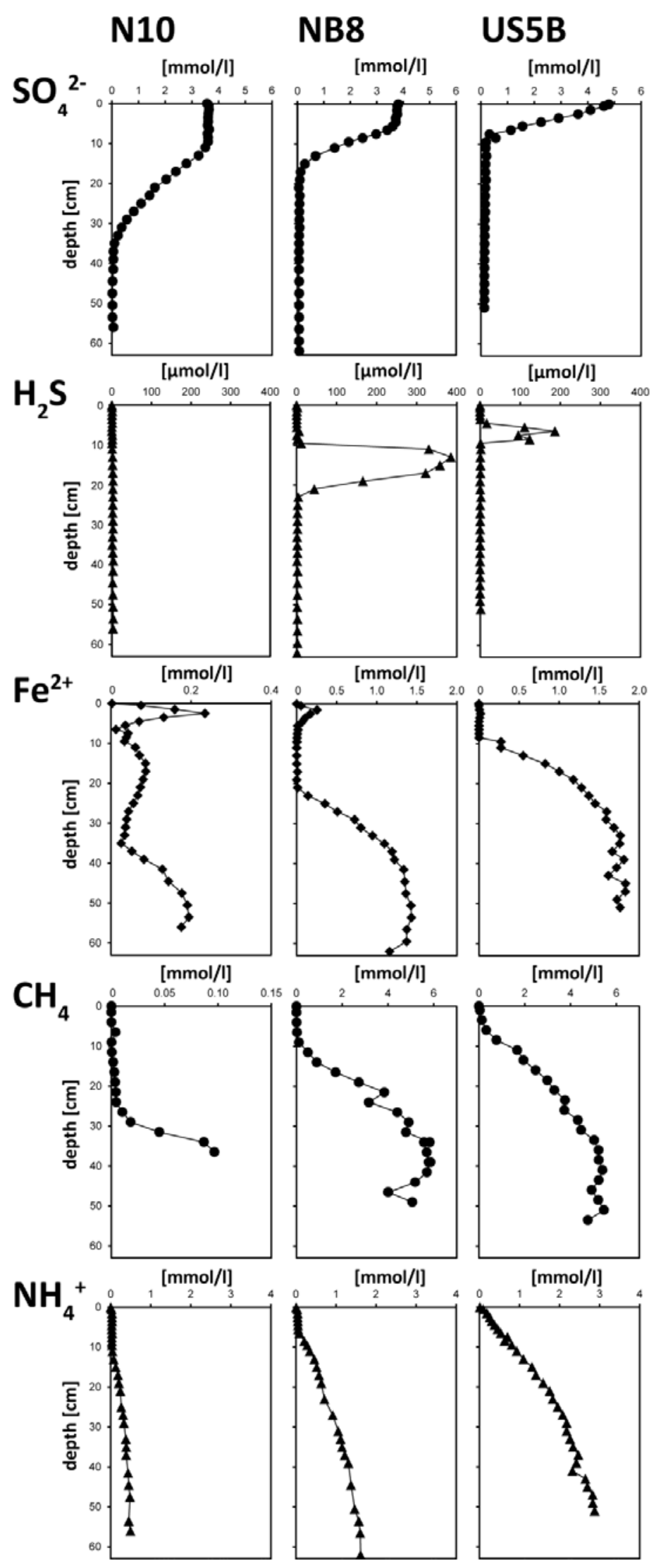




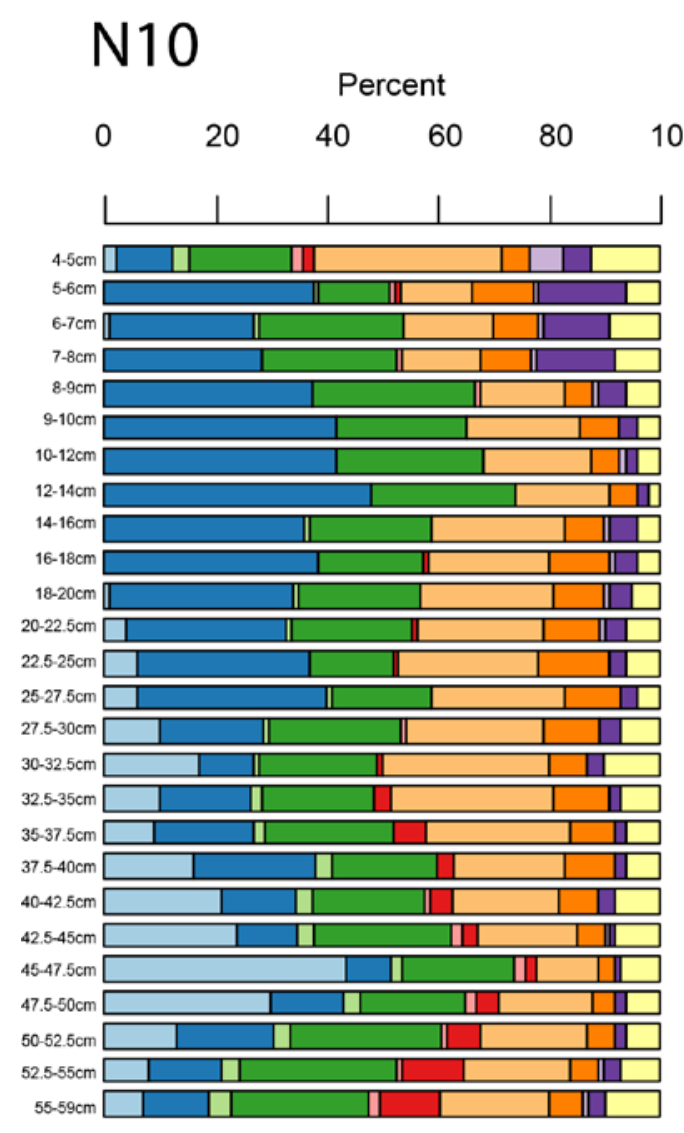

\section{NB8}

Percent

\section{US5B}

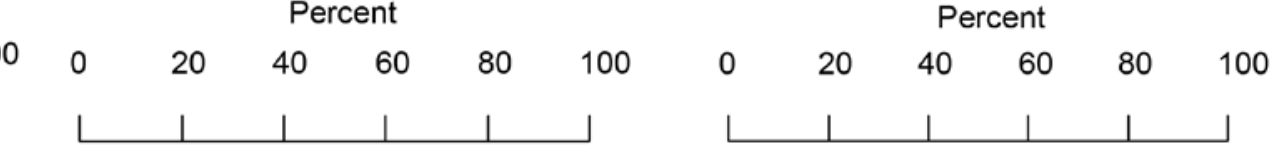

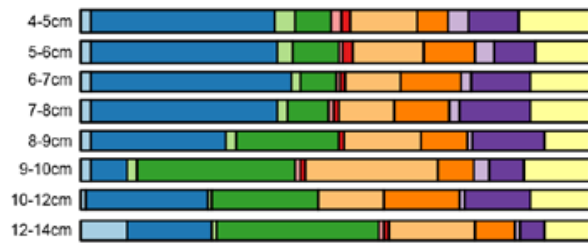

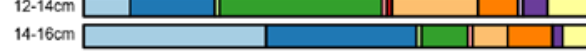
\begin{tabular}{lll}
$14-18 \mathrm{~cm}$ & & \\
\hline
\end{tabular} $18.20 \mathrm{~cm}-1$ |ाI|

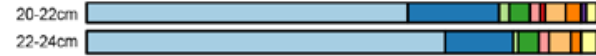
$24-26 \mathrm{~cm}$ $26-28 \mathrm{~cm}$\begin{tabular}{|l|l|l|}
\hline & &
\end{tabular}

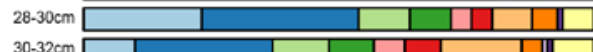

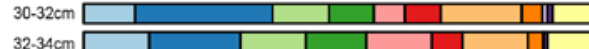
$34.36 \mathrm{~cm}$

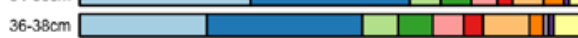
\begin{tabular}{ll|l|l|l|l|}
\hline $38.40 \mathrm{~cm}$ & \\
\hline \hline & & & & &
\end{tabular}

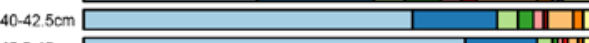
\begin{tabular}{l|l|l|l|l|}
$42.5-45 \mathrm{~cm}$ & \\
\hline & & & \\
\hline
\end{tabular}

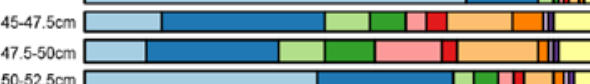

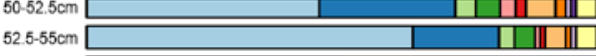
56-57.5cm \begin{tabular}{l|l|l|l|}
\hline & & & \\
\hline
\end{tabular} $2.000 \mathrm{~cm}$

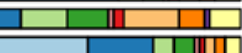
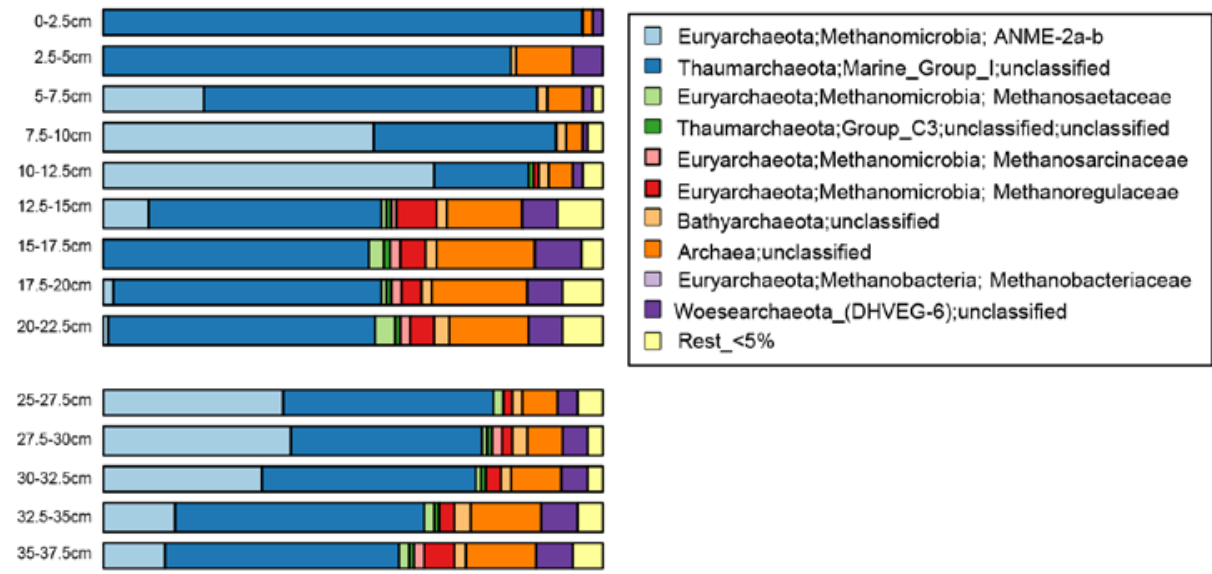

$37.5-40 \mathrm{~cm}$

$40.42 .5 \mathrm{~cm}$

$42.5 .45 \mathrm{~cm}$

$45-47.5 \mathrm{~cm}$

$47.5-50 \mathrm{~cm}$
$50.52 .5 \mathrm{~cm}$

52.5-55 cm

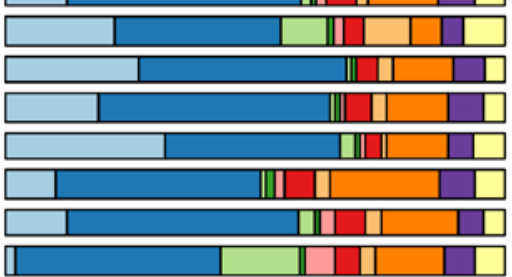

Euryarchaeota;Methanomicrobia; ANME-2a-b

Turyas

Thaumarchaeota:Group_C3:unclassified:unclassified

archaeota; unclassified

Rest_<5\% 


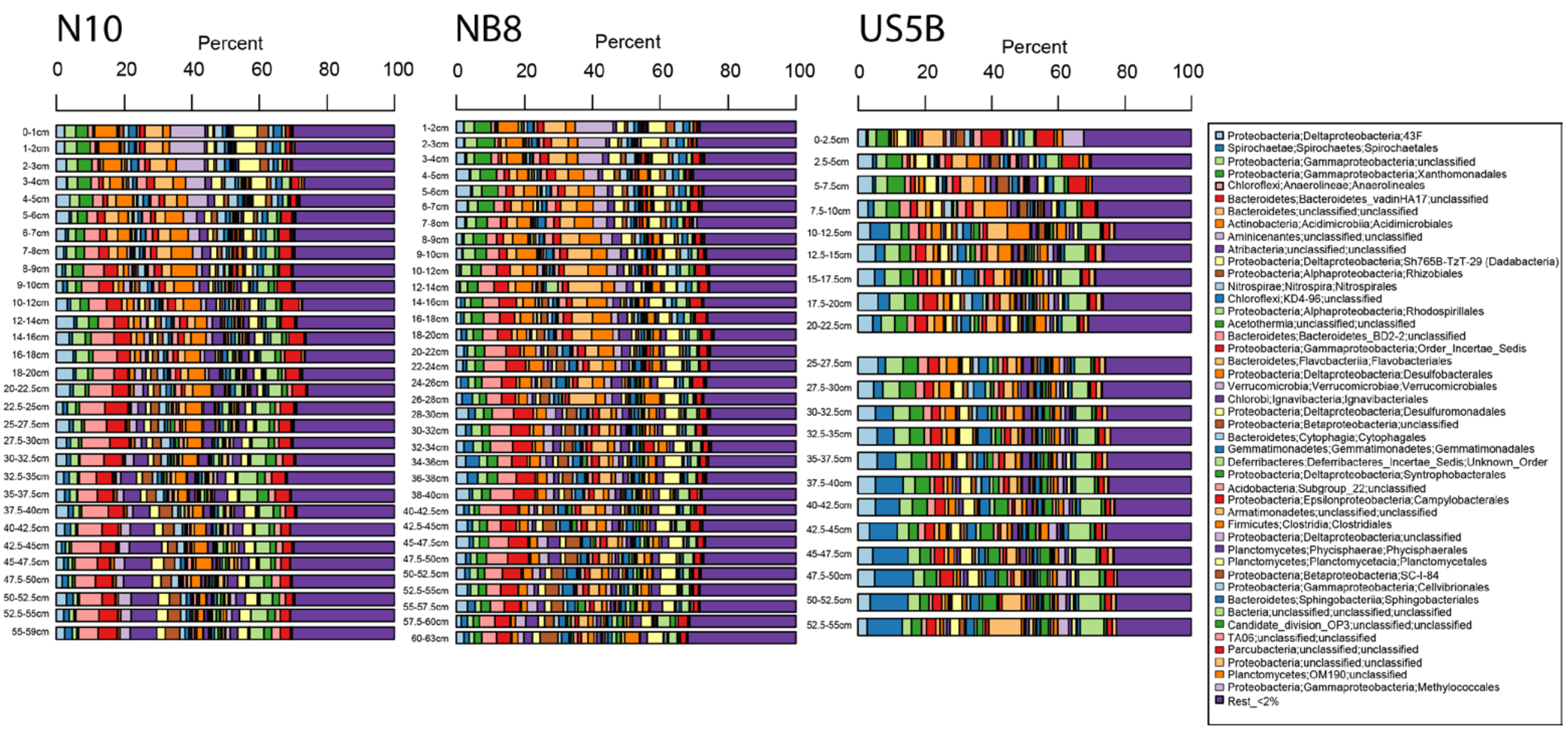



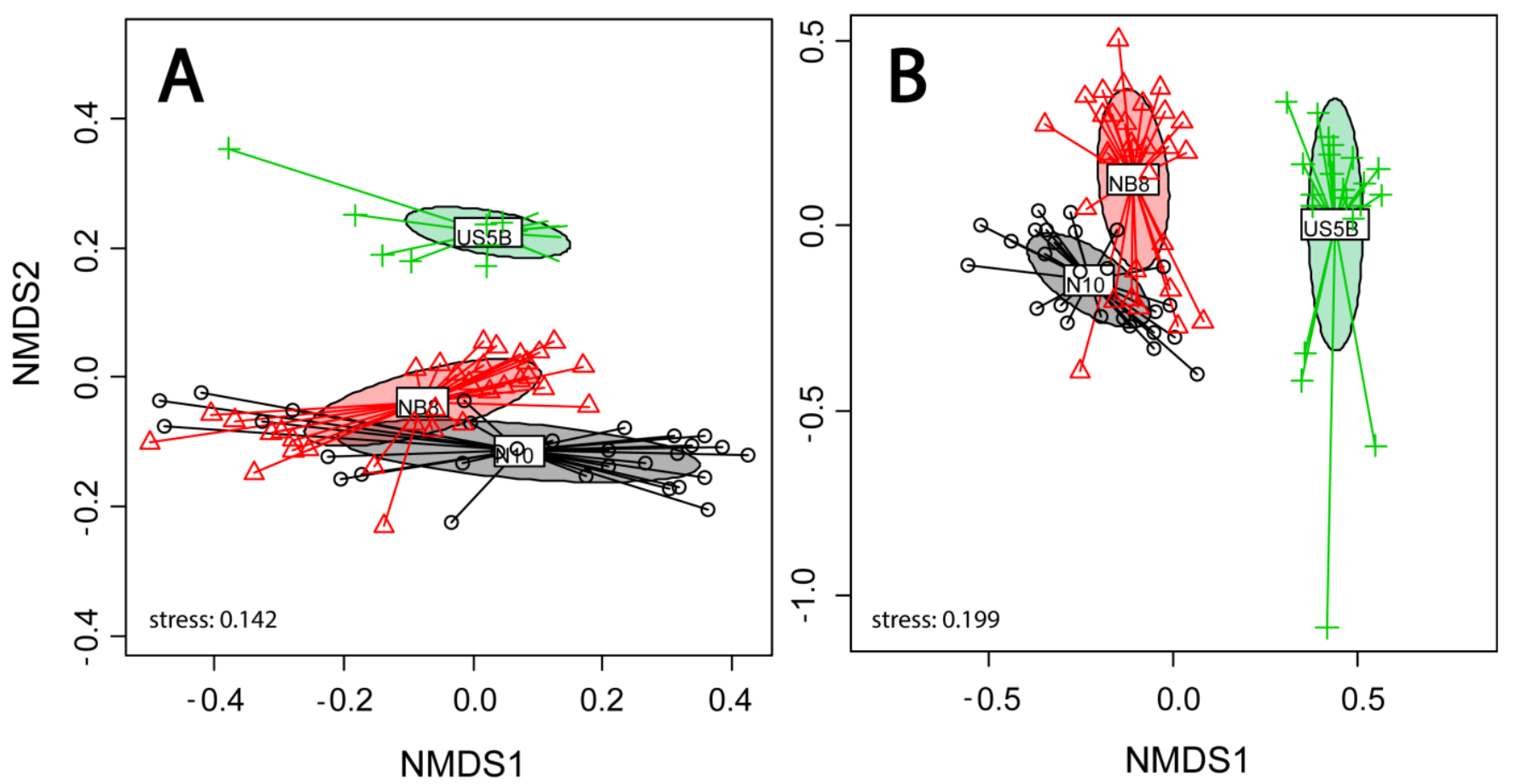
1229 Figure 6

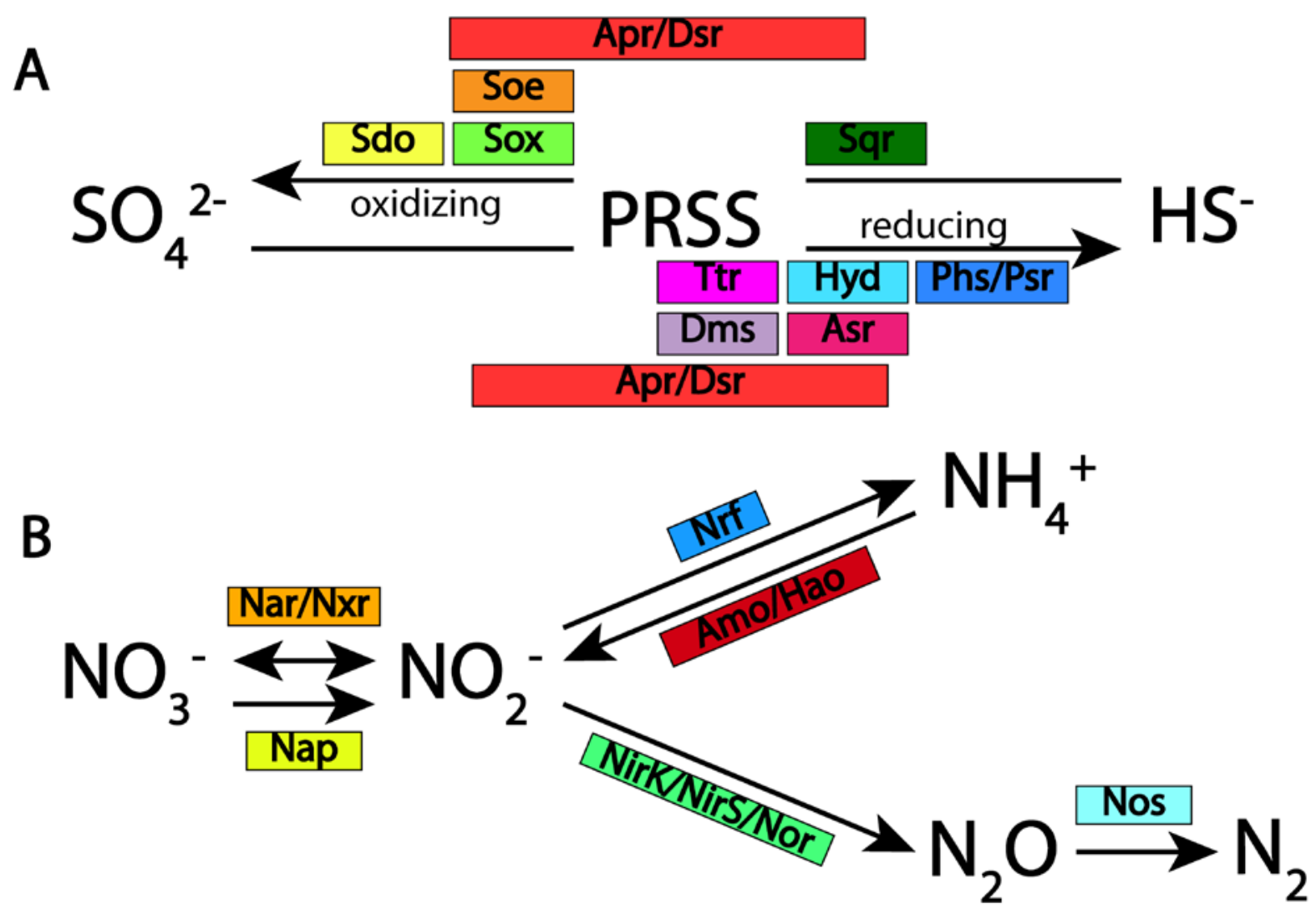


bioRxiv preprint doi: https://doi.org/10.1101/553131; this version posted February 18,2019 . The copyright holder for this preprint (which was not certified by peer review) is the author/funder. All rights reserved. No reuse allowed without permission.

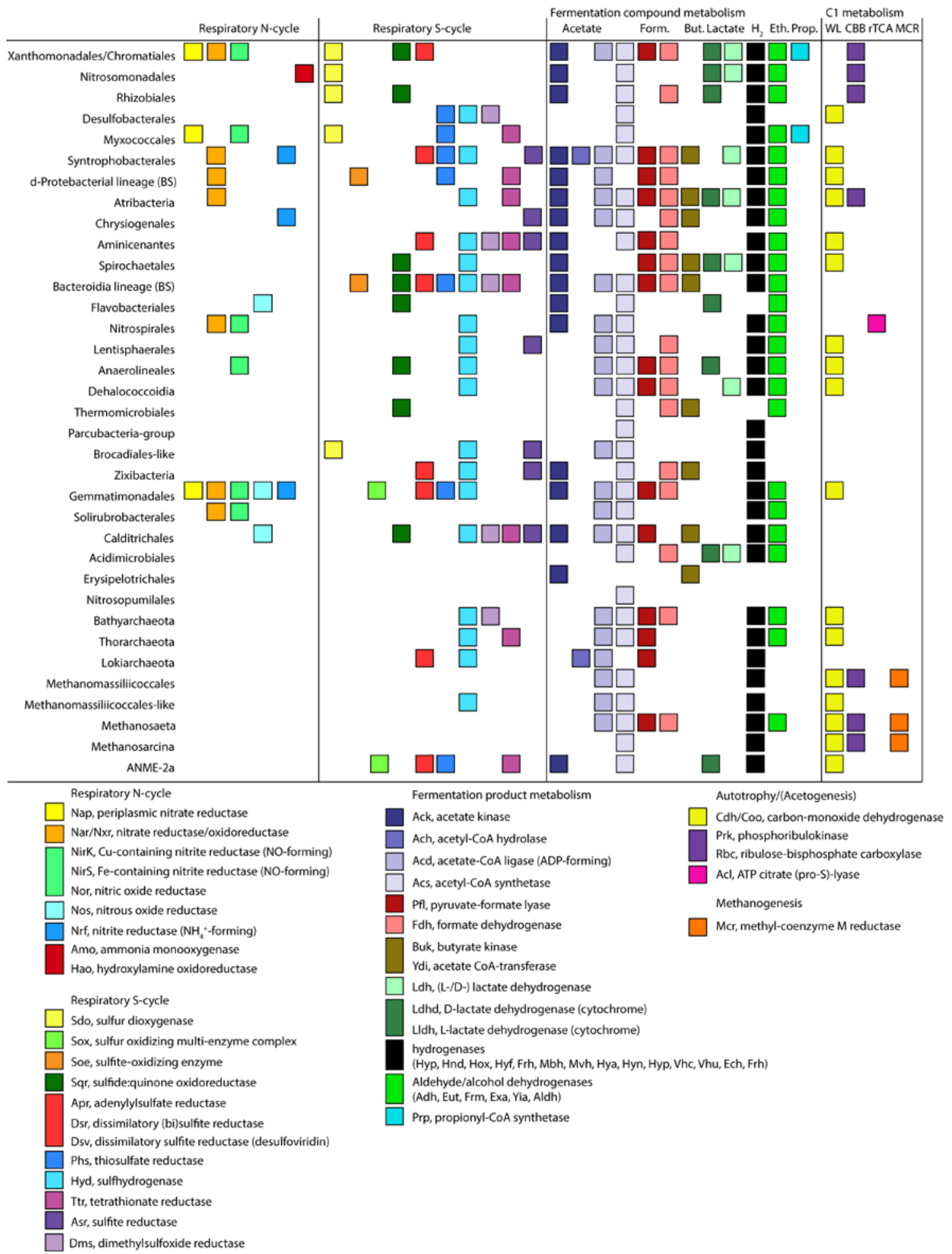


bioRxiv preprint doi: https://doi.org/10.1101/553131; this version posted February 18,2019 . The copyright holder for this preprint (which was not certified by peer review) is the author/funder. All rights reserved. No reuse allowed without permission.

\section{Figure 8}

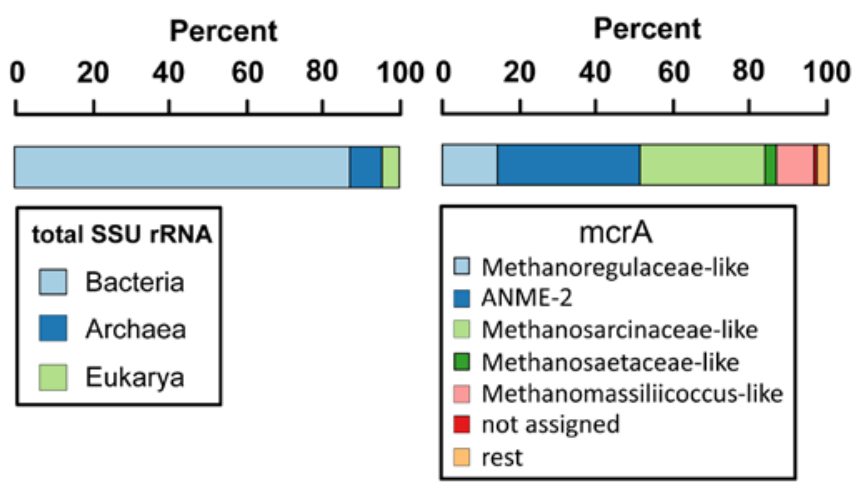

1234 


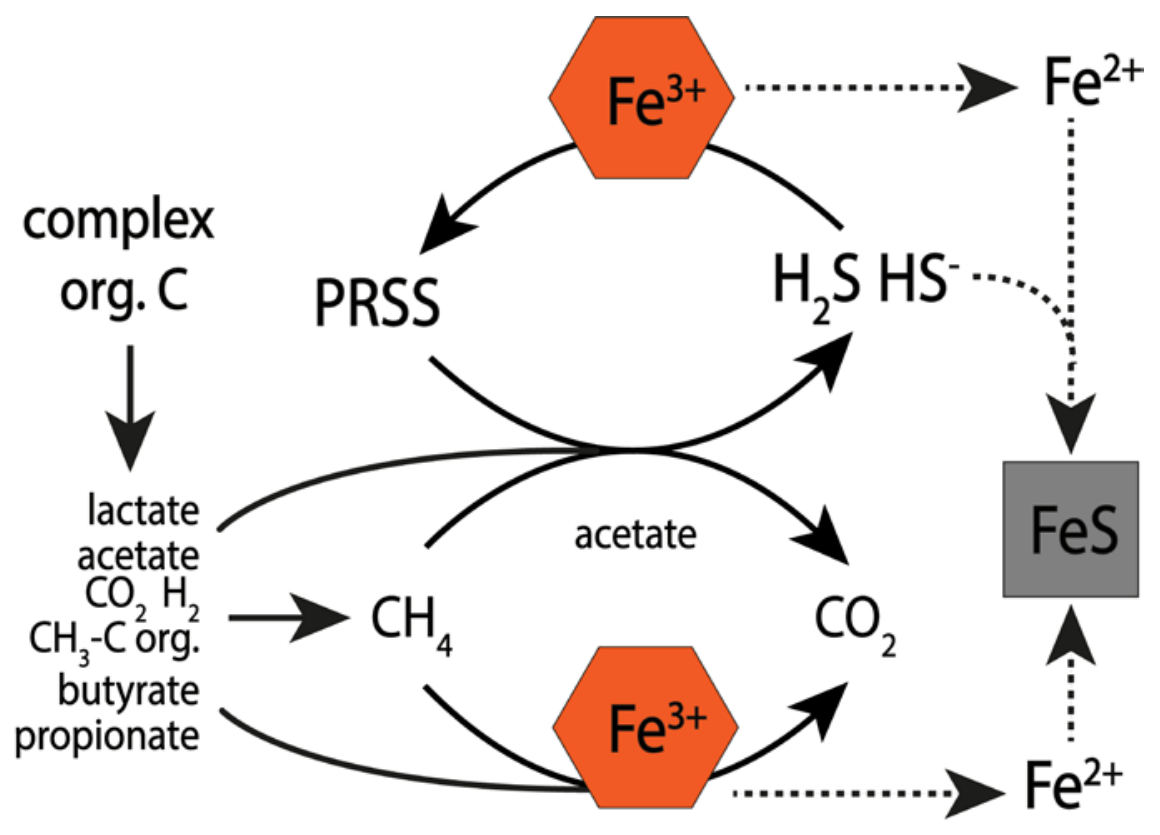

